\title{
Analytical model for the out-of-plane response of vertically spanning unreinforced masonry walls
}

\author{
Michele Godio(D) | Katrin Beyer(D)
}

Earthquake Engineering and Structural Dynamics Laboratory (EESD), School of Architecture, Civil and Environmental Engineering (ENAC), Ecole Polytechnique Fédérale de Lausanne (EPFL), EPFL ENAC IIC EESD, GC B2 495, Station 18, CH-1015 Lausanne, Switzerland

\section{Correspondence}

Katrin Beyer, Earthquake Engineering and Structural Dynamics Laboratory (EESD), School of Architecture, Civil and Environmental Engineering (ENAC), Ecole Polytechnique Fédérale de Lausanne (EPFL), EPFL ENAC IIC EESD, GC B2 495, Station 18, CH-1015 Lausanne, Switzerland.

Email: katrin.beyer@epfl.ch

\section{Funding information}

Swiss Federal Office of the Environment; Construction Department of the Canton Basel-Stadt

\begin{abstract}
Summary
An analytical model describing the flexural response of vertically spanning out-of-plane loaded unreinforced masonry walls is presented in this paper. The model is based on the second-order Euler-Bernoulli beam theory and captures important characteristics of the out-of-plane response of masonry walls that have been observed in experimental tests and from numerical studies but for which an analytical solution was still lacking: the onset and the evolution of cracking, the peak strength of the out-of-plane loaded walls, and the softening of the response due to $P-\Delta$ effects. The model is validated against experimental results, and the comparison shows that the model captures both the prepeak and postpeak response of the walls. From the analytical model of the force-displacement curve, a formula for the maximum out-of-plane strength of the walls is derived, which can be directly applied in engineering practice.
\end{abstract}

\section{KEYWORDS}

analytical model, out-of-plane behaviour, pushover analysis, unreinforced masonry

\section{1 | INTRODUCTION}

Under seismic loading, unreinforced masonry walls, which can be either free standing walls or part of a building, might fail because of in-plane or out-of-plane loading. This paper treats the out-of-plane response of unreinforced masonry walls. Under out-of-plane loading, unreinforced masonry walls first crack and then develop in the postpeak phase of the force-displacement response a rocking mechanism. This rocking mechanism can be rather stable; reaching the peak force does therefore not mark the failure of the wall. ${ }^{1-3}$ Doherty et al. ${ }^{4}$ account for this postpeak response through a displacement-based assessment procedure, which has now been implemented in several assessment guidelines for engineering practice..$^{5-7}$

In displacement-based assessment procedures, out-of-plane loaded walls are often approximated as 2D systems of one-way vertically spanning elements (Figure 1A). The response (or capacity) of these walls is represented by a pushover curve. If the masonry is constructed with dry joints or if the mortar strength has degraded during previous load cycles to such extent that the tensile strength is negligible, the pushover curves have a characteristic round form, which has been observed in several experimental campaigns (Figure 1B). To simplify matters, the pushover curve is often approximated by the use of bilinear or trilinear models. For a given collapse mechanism, bilinear models can be derived from a rigid body kinematic analysis of the wall, ${ }^{3,4,8,9}$ yielding the maximum force $Q_{0}$ and the ultimate displacement $\Delta_{0}$. The same analysis is used to define the third branch of the trilinear model, ${ }^{4,8,10}$ often assuming a certain reduction in the effective width of the wall due to the limited compressive strength of masonry, ${ }^{11}$ which leads to a smaller ultimate deflection $\Delta_{\mathrm{u}}$ than the rigid body analysis. The first and the second branch of the trilinear models are, on the contrary, defined by the ratios $\Delta_{1} / \Delta_{\mathrm{u}}$ and $\Delta_{2} / \Delta_{\mathrm{u}}$. Their values are typically calibrated with experimental results. ${ }^{4,8,10-12}$ 


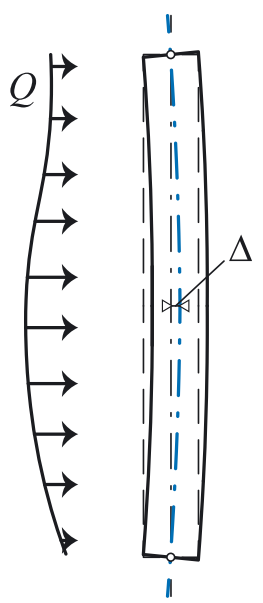

(A)

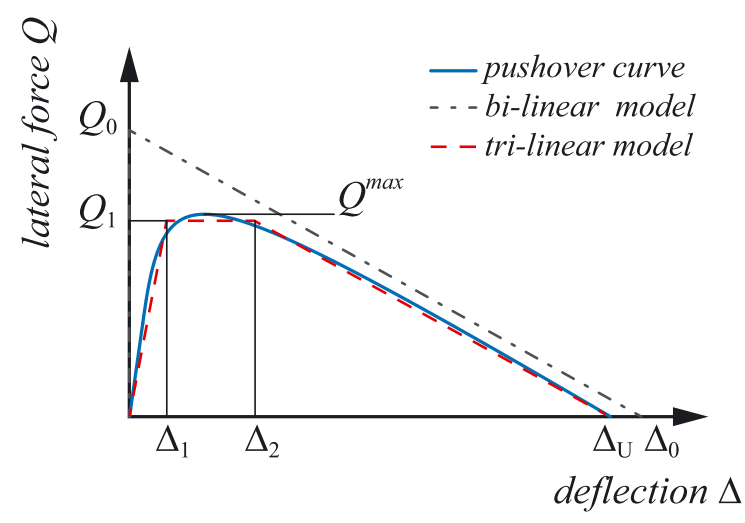

(B)

FIGURE 1 A, Vertically spanning load-bearing masonry wall subjected to out-of-plane loading. B, Pushover curve and bilinear and trilinear approximations (after Doherty et al. ${ }^{4}$ ) [Colour figure can be viewed at wileyonlinelibrary.com]

If a more precise estimate of the pushover curve is required, finite or discrete element simulations have to be performed; for a review on the numerical methods and assessment techniques generally used in this field, we refer to Ferreira et al. ${ }^{13}$ Such numerical models have the advantage of being very versatile. They can be used to analyse a large range of wall configurations, with various geometries and static and kinematic boundary conditions. Furthermore, detailed nonlinear numerical models allow to analyse the wall as a composite structure by representing the mortar layers and bricks (or blocks) explicitly. Such models are, however, computationally expensive and allow only by regression of the analysis results an insight into the controlling parameters of the wall response.

To complement previous research, this paper contributes to the challenge of predicting the out-of-plane response of unreinforced masonry walls by presenting an analytical solution for the complete force-displacement curve of slender vertically spanning walls. The pushover curve is derived by integrating the differential equation of the Euler-Bernoulli beam theory. The equation is formulated to include geometric nonlinearities ( $P-\Delta$ effects) and solved for a masonry material with zero tensile strength and a linear elastic constitutive law in compression. These assumptions have already been made in the 40's and 60's when studying the stability of unreinforced masonry walls subjected to eccentric axial loads. ${ }^{14-16}$ Although such assumptions neglect the interaction between the mortar and the bricks as well as the finite compressive strength of the two materials, they result in a good level of accuracy in modelling the masonry behaviour for many configurations and boundary conditions. ${ }^{16-20}$ They were extensively used in the past to determine the axial force that triggers instability of unreinforced masonry piers and columns. Such studies considered eccentric axial loads ${ }^{17,21-27}$ or combinations of constant lateral loads and increasing axial loads..$^{18-20,28-33}$ In the present paper, these assumptions are used to analyse the out-of-plane behaviour of unreinforced masonry walls when subjected to a constant axial load and a varying lateral load. This approach is used to derive an analytical solution of the pushover curve of the wall, when this latter is subjected to loading conditions similar to those arising in seismic events.

The pushover curve is given in analytical form for vertically spanning unreinforced masonry walls having the following kinematic boundary conditions: pinned-pinned, fixed-fixed, and cantilever. Moreover, two static loading conditions are taken into account: a wall subjected to a constant axial force and either a concentrated or a distributed lateral load. A detailed discussion of the model parameters is given in the paper, and the model response is compared to the solution obtained from the rigid body kinematic analysis and to results from experimental tests. A key finding of this study is the expression for the maximum lateral strength (or peak force) $Q^{\max }$. It is shown that this can be expressed as product of the maximum force derived from rigid body kinematics $\left(Q_{0}\right)$ and a factor, which is a function of the axial load $P$ and the Euler's critical load $P_{\mathrm{E}}$.

The paper commences with the derivation of the principal differential equations of the Euler-Bernoulli beam theory, formulated for no-tension materials and including $P-\Delta$ effects (Section 2). The equations are then solved for a concentrated force applied at midheight of the wall, and a parametric study highlights the influence of principal parameters (Section 3). Section 4 discusses the choice of the model parameters and the modelling of the boundary conditions and validates the solution with experimental results reported in the literature. Section 5 compares the behaviour of walls subjected to a distributed load to that of walls under a concentrated load and shows how the peak strength for the distributed load can be approximated by that for the concentrated force. Based on the analytical model and these findings, a formula for the maximum out-of-plane strength of vertically spanning unreinforced masonry walls is derived for both loading conditions. 


\section{2 | MODEL FORMULATION}

The analytical model herein developed is based on the Euler-Bernoulli beam theory, in which nonlinear geometric (or $P-\Delta$ ) effects are included. It is, therefore, applicable to walls that are rather slender for loading in the out-of-plane direction. Furthermore, masonry is modelled as a material with zero tensile strength and linear elastic behaviour in compression. These assumptions were used in previous studies to investigate the influence of the axial load eccentricity, ${ }^{15,21}$ the effect of initial deflections, ${ }^{16}$ the effect of self-weight, ${ }^{22}$ the presence of uncracked bricks or blocks, ${ }^{23}$ and the influence of lateral loads ${ }^{28,29,31}$ on the buckling capacity of unreinforced masonry walls or columns. In a few studies, they were also used to investigate the lateral response of the walls. ${ }^{19,20,25,33}$ In those studies, however, numerical procedures based on the finite element method ${ }^{19}$, in which the wall was discretized into small elements with constant curvature, ${ }^{20,25,33}$ were used to solve the equations. These studies therefore did not yield general solutions. The objective of this paper is twofold. First, we solve these equations analytically and derive in analytical form the full flexural force-displacement (or pushover) curve of out-of-plane loaded masonry walls. Second, we compare the so-obtained peak force $Q^{\max }$ to the maximum force obtained by rigid body kinematics $Q_{0}$ and derive a simple expression that links $Q^{\max }$ to $Q_{0}$. This expression can be used in engineering practice to estimate $Q^{\max }$ from $Q_{0}$ without performing any advanced analysis.

\section{1 | Basic equations}

We consider a vertical strip of a masonry wall undergoing large out-of-plane deflections. In practice, the slenderness ratio of unreinforced masonry walls in residential construction is sufficiently large to be described by means of an Euler-Bernoulli beam model. With this model and assuming a no-tension material, during bending, plane cross sections of the wall remain plane in the compressed region of the wall ${ }^{31}$ and shear deformations of the masonry are neglected..$^{34}$

Masonry is considered here as a no-tension material. For the behaviour in compression, a linear uniaxial stress-strain relationship is assumed. In previous studies, also nonlinear stress-strain relationships have been used..$^{20,26,30-32}$ The linear constitutive law considered herein is an approximation of the actual material behaviour, whose application is limited to masonry walls with low-to-moderate axial load ratios. This approximation is frequently chosen in studies on the out-of-plane response of masonry walls (eg, previous studies s $^{3,16,28,29}$ ), since the walls that are most susceptible to out-of-plane failure are often those located at the top floors of a building, where horizontal accelerations produced during an earthquake are largest and axial loads are smallest. ${ }^{1}$ The approximation of a linear material behaviour in compression is chosen here because it keeps the formulation simple and renders analytical solutions possible.

We consider a generic wall of height $H$, length $L$, and thickness $t$. At the height $x$, the wall is undergoing an out-of-plane deflection $v(x)$. It is useful to distinguish the cracked part of the wall from the one that remains uncracked (Figure 2). The behaviour of the uncracked part of the wall is described by the differential equation of the second-order Euler-Bernoulli beam theory:

$$
v^{\prime \prime}(x)+\frac{\tilde{M}(x)}{E_{\mathrm{m}} I}=0,
$$

where $E_{\mathrm{m}}$ is the elastic modulus of masonry, $I=L t^{3} / 12$ the moment of inertia of the wall cross section, and $\tilde{M}(x)$ the bending moment at the displaced centre line of the wall, ie, considering large deflections ( $P-\Delta$ effects). Its expression is

$$
\tilde{M}(x)=P\left(v(x)+e_{p}\right)+M(x),
$$

where $P$ is the axial load (positive when in compression) acting at the top of the wall with eccentricity $e_{p}$ and $M(x)$ is the bending moment distribution due to the lateral load only.

For a distributed load, the line of thrust is curved, and for a concentrated load, the line of thrust is piecewise linear. ${ }^{29,35}$ Cracking occurs when the eccentricity of the line of thrust from the centre line of the wall exceeds $t / 6$ :

$$
|\tilde{M}(x)| \geqslant P \frac{t}{6} .
$$

Upon cracking, the effective thickness of the wall reduces to $t_{c}$, and the line of thrust moves towards the edge of the cross section (Figure 2A). Since the material behaviour in compression is assumed to be linear, the stress distribution in the compressed part of the section is always linear ${ }^{16,21}$ (Figure 2B). The differential equation governing the cracked part of the wall can therefore be written as ${ }^{29}$

$$
v^{\prime \prime}(x)+\frac{2 P}{E_{\mathrm{m}} L} \frac{1}{t_{c}^{2}}=0
$$




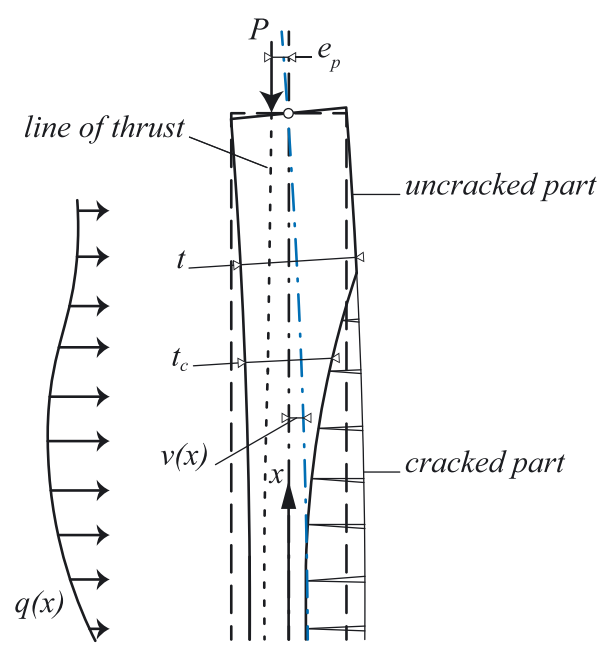

(A) Deformed configuration

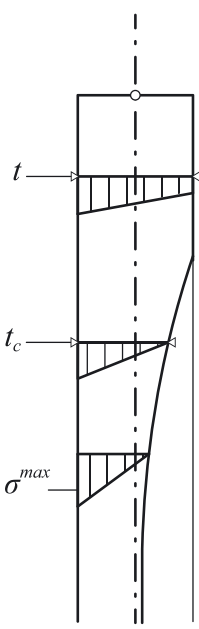

(B) Normal stress distribution assumed by the model

FIGURE 2 Vertically spanning load-bearing masonry wall modelled as an Euler-Bernoulli beam undergoing large out-of-plane deflections and cracking. A, Deformed configuration; B, normal stress distribution assumed by the model [Colour figure can be viewed at wileyonlinelibrary.com]

with

$$
t_{c}=3\left(\frac{t}{2}-\frac{\tilde{M}(x)}{P}\right)
$$

denoting the depth of the compressed region of the cross section (Figure 2, left). Failure of the wall occurs when $t_{c}$ tends towards zero in at least one of the wall cross sections. ${ }^{16,21,29}$

\section{2 | Remarks}

Equations 1 and 4 are 2 ordinary differential equations describing the behaviour of the uncracked and the cracked part of the masonry wall. These equations are presented here in their most general form, which was derived by Hellers. ${ }^{29}$ From these equations, it follows that not only the lateral load induces bending but, due to the wall deflection, also the axial load. This is a consequence of the second order formulation herein adopted.

If one substituted $\tilde{M}(x)$ by $M(x)$ in the above equations, the effect of large deflections would be annihilated. One would obtain the equations that have been the basis of models for the in-plane behaviour of unreinforced masonry walls, for which $P-\Delta$ effects do not play a significant role. ${ }^{36-38}$ When analysing the out-of-plane behaviour of these walls, large deflections are, on the contrary, essential. ${ }^{7,8}$ For the in-plane behaviour, it is, nevertheless, essential to account for shear deformability. In that case, the Euler-Bernoulli beam model has to be replaced by a Timoshenko beam model. ${ }^{37,38}$

\section{3 | EXAMPLE OF MODEL RESPONSE: WALLS SUBJECTED TO A LATERAL CONCENTRATED LOAD}

Analytical solutions to Equations 1 and 4 were proposed by Sahlin ${ }^{28,39}$ and Hellers ${ }^{29}$ for concentrated lateral loads and distributed loads, respectively. In this paper, these solutions are generalised for different boundary conditions and discussed with respect to those given by simplified models used in seismic engineering, namely the bilinear and trilinear models. ${ }^{4,8}$ In this section, the response of a wall subjected to a lateral load $Q$ at midheight of the wall and an axial load $P$ applied at the top of the wall is studied for 3 different boundary conditions (Figure 3). The case of a distributed load is treated in Section 5.

\section{1 | Response of the uncracked wall}

The behaviour of the wall prior to cracking is found by double-integrating Equation 1. This yields the following closed-form expression of the lateral displacement of the wall:

$$
\delta_{c}=\frac{\beta}{\alpha t}\left[(\sec (\alpha \mu H)-1) e_{p}-\frac{\alpha \beta}{\mu^{3} E_{\mathrm{m}} I}\left(\mu H-\frac{1}{\alpha} \tan (\alpha \mu H)\right) Q\right],
$$




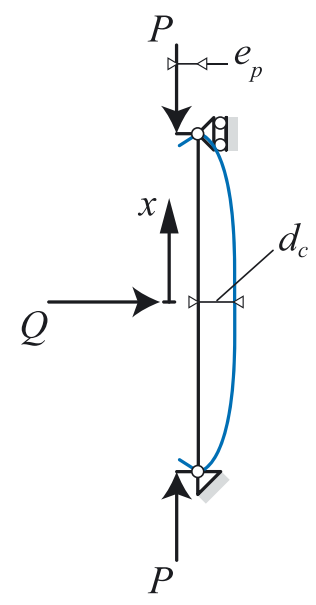

Pinned-pinned
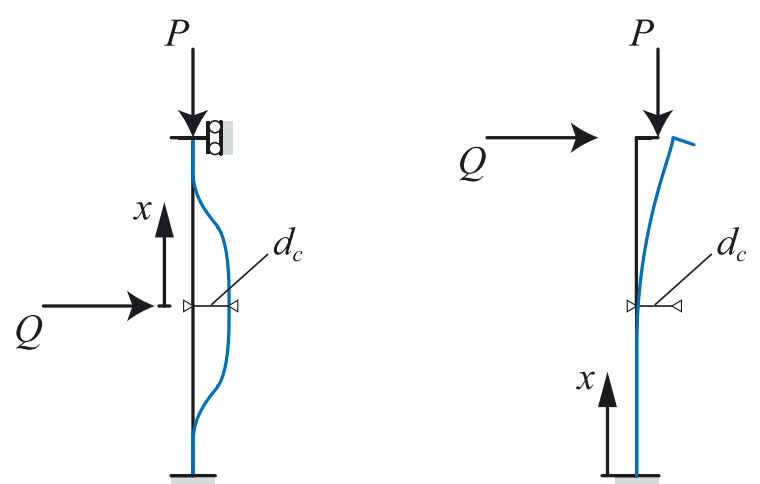

Clamped-clamped

Cantilever

FIGURE 3 Vertically spanning masonry walls undergoing large out-of-plane deflections subjected to a lateral concentrated force for different boundary conditions [Colour figure can be viewed at wileyonlinelibrary.com]

with

$$
\mu=\sqrt{\frac{P}{E_{\mathrm{m}} I}} .
$$

In the above expression, $\delta_{c}$ is the normalised deflection of the wall at the height $x$ where the maximum deflection occurs: $\delta_{c}=d_{c} / t$. This height is in the following referred to as control point. It corresponds to the wall midheight for the pinned-pinned and the clamped-clamped boundary conditions and to the top of the wall for the cantilever wall (Figure 3). Parameters $\alpha$ and $\beta$ depend on the boundary conditions and take the following values: $\alpha=1 / 2, \beta=1 / 2$, for the pinned-pinned wall; $\alpha=1 / 4, \beta=$ $1 / 2$, for the clamped-clamped wall; and $\alpha=1, \beta=1$, for the cantilever wall.

\section{2 | Onset of cracking}

Onset of cracking in the masonry wall occurs when the condition contained in Equation 3 is satisfied in at least one section of the wall. The section in which cracking is triggered is the one where the bending moment $\tilde{M}(x)$ is maximum. In the case of the pinned-pinned wall, cracks appear first at midheight of the wall. In the clamped-clamped wall, cracking occurs simultaneously at midheight and at the ends of the wall. In the cantilever wall, cracking develops starting from the base of the wall. The limit case of Equation 3 yields the expression of the concentrated force at the onset of cracking. This force is denoted with $Q^{e l}$, as it gives the force at which the elastic limit of the material is exceeded (Equations 1 and 3):

$$
Q^{e l}=\frac{1}{\beta}\left(-\mu^{3} E_{\mathrm{m}} I \csc (\alpha \mu H) e_{p}+\frac{\mu}{\tan (\alpha \mu H)} \frac{t}{6} P\right) .
$$

At this point, the normalised deflection is (Equation 3):

$$
\delta_{c}^{e l}=\frac{\beta}{\alpha t}\left(\frac{t}{6}-e_{p}-\frac{M_{c}}{P}\right)
$$

where $M_{c}$ is defined as $M_{c}=\alpha \beta Q H$ and is here evaluated for $Q=Q^{e l}$ (Equation 7).

\subsection{Response of the partially cracked wall}

Sahlin $^{28}$ provided design charts that represent the solution to the problem of the partially cracked wall subjected to concentrated horizontal loads, but they did not provide analytical solutions. ${ }^{28,39}$ Chapman and Slatford ${ }^{16}$ found the analytical solution to Equations 1 and 4 for a partially cracked masonry wall with pinned ends, eccentric axial load, and initial deflection. This solution is herein generalised to the case of a wall subjected to a concentrated lateral load applied at midheight of the wall, giving an alternative solution to the graphical chart by Sahlin. ${ }^{28}$ In addition, 3 different boundary conditions are considered (Figure 3). As in the original work, ${ }^{16,28}$ the solution is given in implicit form: 


$$
\begin{aligned}
\mu \alpha H & -\frac{\mathcal{G}\left(z_{t} l\right)-\mathcal{G}\left(z_{c} l\right)}{\left(\frac{t}{3} l\right)^{3 / 2}+} \\
& -\arcsin \left(\frac{\frac{t}{2}-z_{t}}{\sqrt{\left(\frac{t}{2}-z_{t}\right)^{2}+\left(\frac{\psi}{\mu}\right)^{2}}}\right)+\arcsin \left(\frac{e_{p}}{\sqrt{\left(\frac{t}{2}-z_{t}\right)^{2}+\left(\frac{\psi}{\mu}\right)^{2}}}\right)=0,
\end{aligned}
$$

where $\mathcal{G}(u)$ is the function:

$$
\mathcal{G}(u)=\sqrt{u-1} \sqrt{u}+\log (\sqrt{u-1}+\sqrt{u}),
$$

and

$$
\begin{aligned}
C & =\frac{\mu^{2} t^{3}}{54} \\
l & =\frac{1}{2 C}\left(\beta \frac{Q}{P}\right)^{2}+\frac{1}{z_{c}} \\
\psi & =\sqrt{2 C\left(l-\frac{1}{z_{t}}\right)},
\end{aligned}
$$

with

$$
z_{t}=\frac{t}{3}, \quad z_{c}=\frac{t}{2}-u_{c} .
$$

In the above expressions, $u_{c}$ is the distance between the thrust line and the axis of the wall in its deformed configuration (Figure 2A). This quantity is measured at the control point of the wall (Figure 3). The normalised deflection of the wall at this point is

$$
\delta_{c}=\frac{\beta}{\alpha t}\left(u_{c}-e_{p}-\frac{M_{c}}{P}\right),
$$

where $M_{c}=\alpha \beta Q H$ is now a function of $Q$ (cf Equation 8). Substitution of Equation 10 into Equation 9 allows to plot in an implicit manner the response of the wall in terms of the applied load $Q$ and deflection $d_{c}=\delta_{c} t$; the axial load $P$ is kept fixed.

Starting from Equation 4, it is also possible to retrieve the analytical expression of the boundary of the cracking zone of the wall in function of the applied loads $P$ and $Q$. One obtains

$$
x\left(\lambda_{d}\right)=\frac{\mathcal{G}\left(\left(1-\lambda_{d}\right) \frac{t}{3} l\right)-\mathcal{G}\left(z_{c} l\right)}{\mu \alpha\left(\frac{t}{3} l\right)^{3 / 2}},
$$

where $\lambda_{d}=\left(t-t_{c}\right) / t$ is the normalised length of the cracked (or decompressed) region of the cross section. A similar equation describes the maximum compression stress occurring at the height $x$, on the outer fibre of the cross section in the cracked part of the wall (Figure 2B):

$$
x\left(\sigma^{\max }\right)=\frac{\mathcal{G}\left(\frac{2}{3} \frac{P}{\sigma^{\max } L} l\right)-\mathcal{G}\left(z_{c} l\right)}{\mu \alpha\left(\frac{t}{3} l\right)^{3 / 2}} .
$$

The above equation is obtained by imposing that, upon cracking: $z_{t}=t_{c} / 3$.

\subsection{Formation of the collapse mechanism}

Figure 4 shows the whole flexural response (pushover curve) of the wall for the 3 boundary conditions considered. The curves are derived for a wall with the following properties: $H=3 \mathrm{~m}, L=3 \mathrm{~m}, t=0.25 \mathrm{~m}, E_{\mathrm{m}}=500 \mathrm{MPa}, \rho=1800 \mathrm{~kg} / \mathrm{m}^{3}$. The curves are normalised by dividing the horizontal force $Q$ by the self-weight of the wall $W$ and the displacement $d_{c}$ by the wall thickness $t$. The axial load is $P=1.12 \mathrm{~W}$ and is applied with zero eccentricity: $e_{p}=0 \mathrm{~m}$. For the pinned-pinned wall, the evolution of cracking within the wall (Equation 11) is shown also in Figure 4A. The self-weight is not included in the analytical model as 

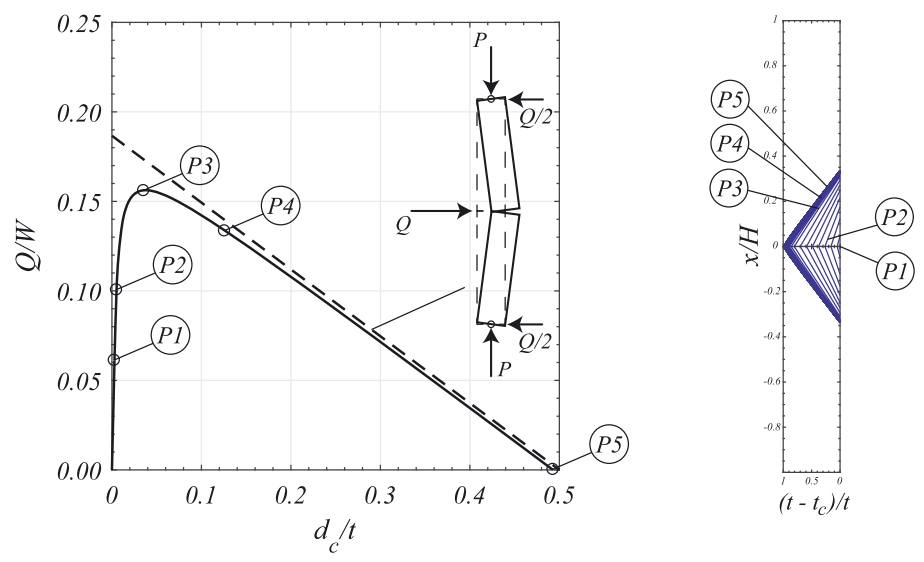

(A) Pinned-pinned

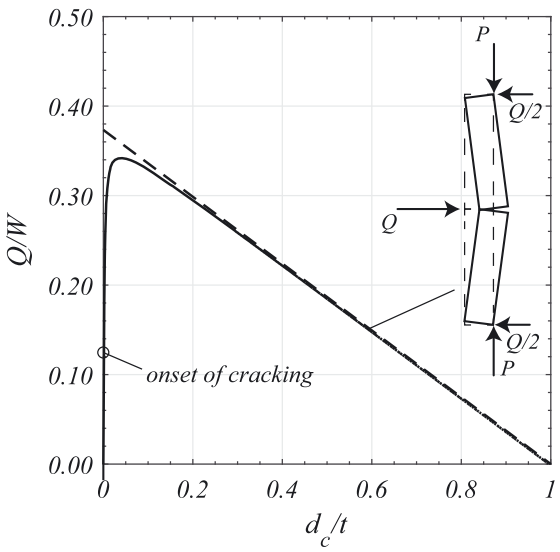

(B) Clamped-clamped

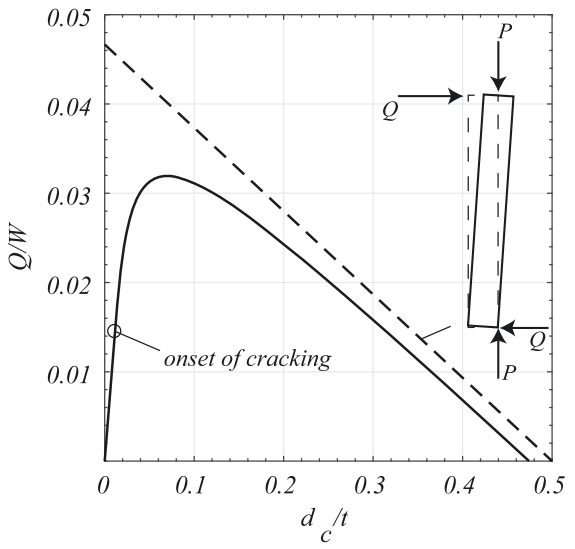

(C) Cantilever

FIGURE 4 Force-displacement curves of vertically spanning masonry walls subjected to a lateral concentrated load: model response (Equations 6 and 9, solid lines), evolution of cracking (Equation 11, blue lines in A) and comparison with the bilinear model derived from the rigid body kinematic analysis ${ }^{4,8}$ (dashed lines) [Colour figure can be viewed at wileyonlinelibrary.com]

distributed gravity load over the wall height but can be treated as an additional axial load applied at the top of the wall. For further details on how to include the contribution of the self-weight in the wall response, the reader is referred to Appendix A.

For small values of the lateral load $\left(Q<Q^{e l}\right)$, all wall sections are fully compressed and the wall response can be entirely described by Equation 6. When the force reaches $Q^{e l}$ (Equation 7), cracking occurs for the first time in one (pinned-pinned, cantilever) or three (clamped-clamped) sections of the wall. At this stage (point $P 1$ of Figure 4A), the response is described by Equation 9. With increasing deflection, the compressed area of these critical cross sections reduces progressively (Equation 5) and the response reaches the peak. However, cracking is not confined to the sections where it first initiated, but it spreads along the wall height (points $P 2$ to $P 3$ and $P 4$ ). The ultimate displacement of the wall is finally reached when the critical sections are fully cracked (point $P 5)$. At this stage, the line of thrust falls on the edge of the wall in the critical cross sections $\left(L_{c} \rightarrow 0\right.$, Figure 4A) and a mechanism is formed.

Because of the spread of the cracking zone, the mechanism forms progressively. Note that the complete formation of the collapse mechanism does not correspond to reaching the peak force, but it occurs at a later stage (point $P 4$ ). After reaching the peak, the wall response tends towards the curve of the bilinear model, which can be derived from a rigid body kinematic analysis of the wall. ${ }^{4,8}$

\section{5 | Study of the model parameters}

The analytical model depends only on few parameters that describe the geometry, material properties, and boundary conditions. Figure 5 highlights the effect of each model parameter on the wall force-displacement response. The case of a pinned-pinned wall is taken as an example. Starting from the reference configuration described in Section 3.4, which is represented by solid lines in Figure 5, each parameter is varied and its effect on the wall response is illustrated. 

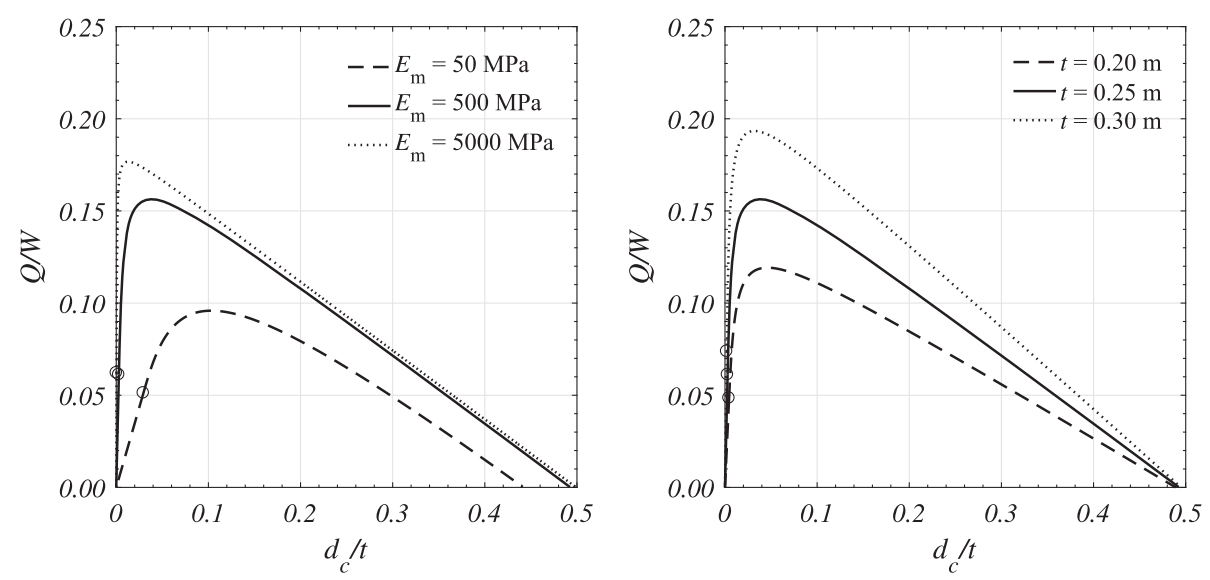

(A) Modulus of elasticity $E_{\mathrm{m}}$

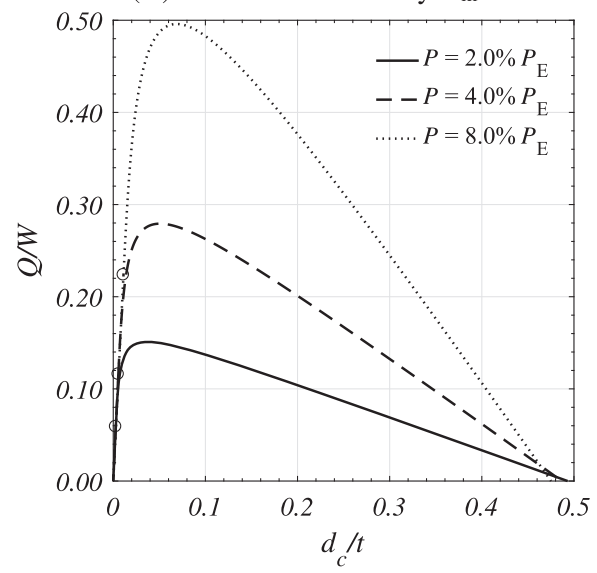

(C) Axial load $P$
(B) Wall thickness $t$

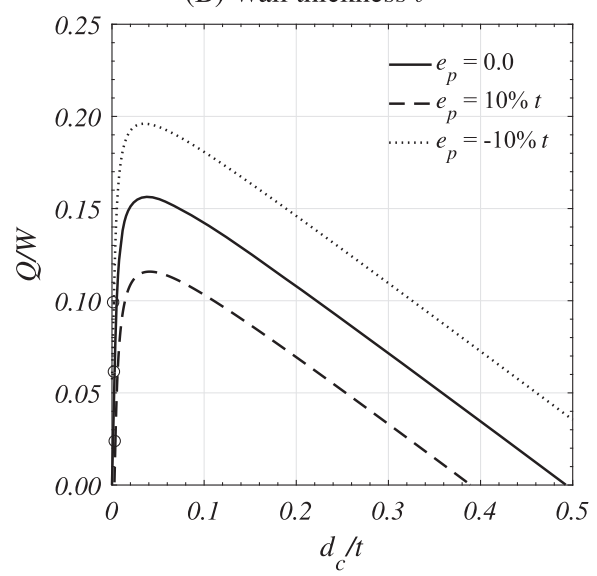

(D) Load eccentricity $e_{p}$

FIGURE 5 Study of the model parameters in the case of a pinned-pinned wall

Figure 5A shows that both the lateral stiffness and the lateral strength (or peak force) of the wall increase with increasing elastic moduli. However, the collapse mechanisms that form upon cracking remain the same. Accordingly, for higher values of $E_{\mathrm{m}}$, the peak force is reached for smaller deflections. This suggests that the parameters $\Delta_{1} / \Delta_{\mathrm{u}}$ and $\Delta_{2} / \Delta_{\mathrm{u}}$ that are used to define the trilinear model ${ }^{4,8}$ should depend on the material properties of the wall. Figure $5 \mathrm{~B}$ shows the well-known effect that increasing the wall thickness (or decreasing the wall slenderness ratio) leads to an increase of its lateral stiffness and strength. The ultimate displacement of approximately $t / 2$ can be easily confirmed by kinematic rigid body analysis. ${ }^{4,8}$ Figure 5C shows the pushover curve for different values of axial load. This load is expressed as a fraction of the Euler's critical load:

$$
P_{\mathrm{E}}=\frac{\pi^{2} E_{\mathrm{m}} I}{(\kappa H)^{2}}
$$

where $\kappa$ is equal to 1 for the pinned-pinned, $1 / 2$ for the clamped-clamped, and 2 for the cantilever wall. For low values of $P$, an increase of axial load is beneficial to the wall strength. However, the trend is inverted for high values of $P$, that is, the strength (or peak force) reduces when $P$ is increased. The inversion of trend occurs at approximately $40 \%$ to $50 \% P_{\mathrm{E}}$ and is not illustrated here. It is the result of the increasingly destabilising effect of the axial load, which can lead to premature instability failure of the wall. ${ }^{26,31}$ In the kinematic analysis underlying the bilinear model, $P$ is only treated as a restoring force, see for instance Derakhshan et al., ${ }^{11}$ while the stability problem is not considered. As a result, an increase in axial force leads to a linear increase in lateral strength. ${ }^{4,8}$ The influence of the axial load on the lateral strength of the wall is investigated further in Section 5. The influence of the load eccentricity is shown in Figure 5D. Depending of the sign of the eccentricity, this latter can increase or decrease the lateral strength of the wall. 


\section{4 | MODEL VALIDATION}

In this section, the analytical model is validated by comparing the analytical force-displacement curves to the experimental pushover curves obtained by the tests described by Doherty et al. ${ }^{40,41}$

\section{1 | Description of the test setup}

A series of quasistatic monotonic pushover tests was performed on vertically spanning unreinforced single-leaf solid clay brick masonry walls at the University of Adelaide. ${ }^{40,41}$ All walls had a height $H=1500 \mathrm{~mm}$, a length of $L=950 \mathrm{~mm}$, and a nominal thickness $t_{\mathrm{n}}$ of 110 or $50 \mathrm{~mm}$. The mass density was 1800 and $2300 \mathrm{~kg} / \mathrm{m}^{3}$ for the specimens with thicknesses of 110 and $50 \mathrm{~mm}$, respectively. The walls were built into a steel frame. At the base, the bricks were placed onto a straight steel surface. At the top, the bricks were supported on both sides by steel angles (Figure 6B). A concentrated lateral load was applied at midheight of the wall, and the displacement at midheight was gradually increased. In some test configurations, also a vertical precompression stress was applied at the top of the wall, which was kept approximately constant throughout the test.

Four different wall configurations were tested. Three of the 4 configurations are modelled here, namely, 100 -mm-thick walls with no overburden (Configuration 1); 50-mm-thick walls with no overburden (Configuration 2); and 50-mm-thick walls with slight overburden (Configuration 3). The fourth configuration with 110-mm-thick walls and overburden is not taken into account. The experimental curves for walls belonging to this configuration exhibit large peaks of lateral force, which were traced back by Doherty to a nonconstant level of overburden exerted by the test rig at large wall deflections. ${ }^{40}$

The material properties of each specimen and configuration are given in Table 1 , where $E_{\mathrm{w}}$ is the modulus of elasticity as obtained from compression tests on masonry wallettes built with the same material as used for the walls, $f_{c}$ is the masonry compressive strength, and $f_{t}$ is the flexural tensile strength of the masonry as obtained from bond wrench tests. The axial load ratio is defined as the ratio between the precompression stress and the compressive strength. Only specimens in which mortar joints had already been cracked (or opened) due to previous dynamic tests on the same specimens are used here for model validation. On one hand, these specimens were precracked (or predamaged) and therefore exhibited zero tensile strength at

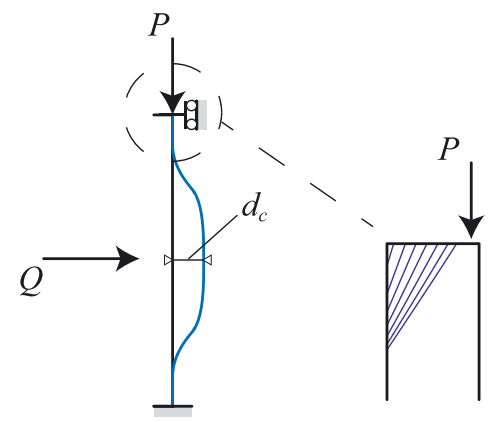

(A) Analytical model

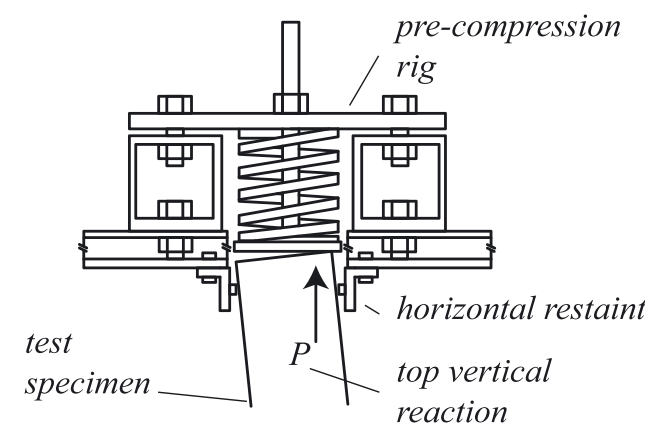

(B) Tested configuration (after Doherty ${ }^{40}$ )

FIGURE 6 Schematic illustration of the boundary conditions and the position of the vertical reaction force at the top of the wall: A, modelled and $\mathrm{B}$, tested configuration [Colour figure can be viewed at wileyonlinelibrary.com]

TABLE 1 Properties of the brick masonry walls used in pushover tests performed at the University of Adelaide ${ }^{40}$

\begin{tabular}{cccccl}
\hline Configuration 1 & $\boldsymbol{E}_{\mathbf{w}}$ & $\boldsymbol{f}_{\boldsymbol{t}}$ & $\boldsymbol{f}_{\boldsymbol{c}}$ & Axial load ratio & Joints condition \\
\hline Specimen 11 & $6600 \mathrm{MPa}$ & $0.32 \mathrm{MPa}$ & $14.2 \mathrm{MPa}$ & $0 \%$ & cracked \\
Specimen 12 & $11600 \mathrm{MPa}$ & $0.30 \mathrm{MPa}$ & $15.7 \mathrm{MPa}$ & $0 \%$ & cracked \\
\hline Specimen 13 & $11600 \mathrm{MPa}$ & $0.29 \mathrm{MPa}$ & $15.7 \mathrm{MPa}$ & $0 \%$ & cracked \\
\hline Configuration 2 & $\boldsymbol{E}_{\mathrm{w}}$ & $\boldsymbol{f}_{\boldsymbol{t}}$ & $\boldsymbol{f}_{\boldsymbol{c}}$ & axial load ratio & joints condition \\
Specimen 10 & $9800 \mathrm{MPa}$ & $0.70 \mathrm{MPa}$ & $26.7 \mathrm{MPa}$ & $0 \%$ & cracked \\
\hline Specimen 14 & $6700 \mathrm{MPa}$ & $0.76 \mathrm{MPa}$ & $26.3 \mathrm{MPa}$ & $0 \%$ & cracked \\
Configuration 3 & $\boldsymbol{E}_{\mathrm{w}}$ & $\boldsymbol{f}_{\boldsymbol{t}}$ & $\boldsymbol{f}_{\boldsymbol{c}}$ & axial load ratio & joints condition \\
\hline Specimen 10 & $9800 \mathrm{MPa}$ & $0.70 \mathrm{MPa}$ & $26.7 \mathrm{MPa}$ & $0.28 \%$ & cracked \\
\hline Specimen 14 & $6700 \mathrm{MPa}$ & $0.76 \mathrm{MPa}$ & $26.3 \mathrm{MPa}$ & $0.57 \%$ & cracked \\
\hline
\end{tabular}


the joints, which is consistent with the model herein proposed. On the other hand, the experimental curves obtained from the pushover tests on predamaged walls are very close to the envelope curves of walls subjected to dynamic horizontal support motion, ${ }^{40}$ see also other works. ${ }^{8,41,42}$

\section{2 | Modelling of the boundary conditions}

The boundary conditions at the bottom and the top of the wall have a large effect on the out-of-plane response of unreinforced masonry walls. ${ }^{43,44}$ The boundary conditions used in the tests by Doherty et al. aimed at representing existing connections between the masonry walls and reinforced concrete floor slabs. ${ }^{40,41}$ In this test setup, the position of the vertical reaction force at the ends of the wall results from the contact between the specimen and the testing rig. As a consequence, upon deflection, the reaction force can move within the wall thickness, ${ }^{40,41}$ see Figure 6B. For this reason, the walls tested by Doherty et al. ${ }^{40}$ are herein modelled as Euler-Bernoulli beams with clamped-clamped boundary conditions (Figure 6A). The wall self-weight is treated as an additional axial load at the top of the wall and set equal to half the wall self-weight (Appendix A).

\section{3 | Choice of the model parameters}

The walls tested in previous stdies $\mathrm{s}^{40,41}$ have precise geometric characteristics and clear boundary conditions that can be straightforwardly reflected in the analytical model. However, two parameters require deeper investigation. These are the effective wall thickness, $t$, and the modulus of elasticity of masonry, $E_{\mathrm{m}}$. These parameters are briefly discussed in the following paragraphs.

\subsection{1 | Effective wall thickness}

The nominal thickness of the wall is generally associated to brick geometry. On the contrary, the effective thickness is determined by the actual depth of the mortar layer (mortar pointing ${ }^{11,12}$ ). As shown in Section 3.5, the effective thickness can highly affect the out-of-plane behaviour of masonry, in such a way that it determines the initial stiffness, the strength, and the ultimate displacement attained by the wall. The amount of pointing depends on the building technique used for the specimen, and consequently, it can be directly estimated or measured. Derakhshan et al. ${ }^{12}$ visually estimated a reduction of the nominal thickness due to pointing of $20 \mathrm{~mm}$ when calibrating the trilinear model for 2- and 3-leaf masonry walls, which had nominal thicknesses of 230 and $350 \mathrm{~mm}$.

The effective walls thickness can also be reduced as a result of the cyclic loading. The crushing of the brick corners and the inelastic deformations of the mortar layers are among the causes of such a progressive reduction of the effective wall thickness. ${ }^{3,11,12,45}$ To this purpose, Doherty ${ }^{40}$ proposed to distinguish new joints from moderately and severely degraded ones and adjusted the parameters of the trilinear model based on experimental findings, see also Doherty et al. ${ }^{4}$

A reduction of the effective thickness was also observed for stone masonry walls. A decrease of effective thickness by $20 \%$ was observed in the tests conducted by Candela et al ${ }^{46}$ on cantilever stone masonry walls (see Lagomarsino ${ }^{3}$ ). In the case of stone masonry, the reduction of thickness can also be the result of a more severe splitting crack developing through the core of the wall and leading the outer leaves of the wall to respond rather independently from the inner leave. This phenomenon was observed by de Felice ${ }^{47}$ by means of discrete elements models applied to multileaf stone masonry walls. In this case, the reduction of thickness was estimated to be up to $50 \%$ of the nominal one.

During the tests performed by Doherty et al. ${ }^{40,41}$ a reduction of the effective thickness was observed only for Specimen 11, due to the drop out of mortar during wall bending..$^{40}$ For this specimen, the value of effective thickness to be used in the model is retrieved by fitting the postpeak response of the experimental curves with the curve from the rigid body analysis. The collapse mechanism considered is shown in Figure 4B, which was also observed in the tests. ${ }^{40}$ The curve from rigid body analysis is fitted between $0.9 Q^{\max }$ and $0.7 Q^{\max }$ of the experimental curve. This results in $t=0.88 t_{\mathrm{n}}$ for Specimen 11 . For the other specimens, $t=t_{\mathrm{n}}$ is used.

\subsection{2 | Masonry elastic modulus}

Masonry is herein modelled as a continuum medium. Its modulus of elasticity is therefore equivalent to that of the composite material constituted of mortar layers and bricks. The study of the model parameters showed that $E_{\mathrm{m}}$ affects not only the lateral stiffness but also the strength (or peak force) of the wall (Section 3.5). The mechanism of collapse that develops remains, nevertheless, the same. 
The tests performed by Doherty et al..$^{40,41}$ have highlighted that the stiffness of masonry walls degrades significantly when the wall is subjected to out-of-plane cycles. This results in a considerably lower initial stiffness. ${ }^{40}$ Estimating the elastic modulus from compression tests on masonry wallettes therefore overestimates the stiffness of the damaged wall. ${ }^{40}$ This was also observed by Derakhshan et al., ${ }^{12}$ where the results from quasistatic cyclic tests performed on multileaf unreinforced masonry walls showed a reduction of stiffness of $80 \%$ and $96 \%$, for walls with and without axial load applied, respectively. This value was measured as the ratio between the initial stiffness of the damaged walls and the initial stiffness of the undamaged walls. ${ }^{12}$ The slightly smaller reduction for walls with axial load was attributed to the confinement of the mortar by the bricks that are in compression, which induced an increase of apparent elastic modulus. ${ }^{12}$ These trends were confirmed by a series of in situ tests performed by the same authors on undamaged reinforced and unreinforced masonry walls. ${ }^{45}$ When the axial elongation was partially restrained and an arching action led to a significant axial load, the stiffness corresponded to $12 \%$ of the undamaged initial stiffness. When

TABLE 2 Parameters used in the analytical model for the modelling of the pushover tests ${ }^{40}$

\begin{tabular}{cccccc} 
Configuration 1 & $\boldsymbol{K}_{\mathbf{u}}$ & $\boldsymbol{K}_{\mathbf{d}}$ & $\boldsymbol{K}_{\mathbf{d}} / \boldsymbol{K}_{\mathbf{u}}$ & $\boldsymbol{E}_{\mathbf{m}}$ & $\boldsymbol{E}_{\mathbf{m}} / \boldsymbol{E}_{\mathbf{w}}$ \\
\hline Specimen 11 & $39.6 \mathrm{MN} / \mathrm{m}$ & $0.2 \mathrm{MN} / \mathrm{m}$ & $0.5 \%$ & $48 \mathrm{MPa}$ & $0.7 \%$ \\
Specimen 12 & $69.5 \mathrm{MN} / \mathrm{m}$ & $0.3 \mathrm{MN} / \mathrm{m}$ & $0.4 \%$ & $43 \mathrm{MPa}$ & $0.4 \%$ \\
Specimen 13 & $69.5 \mathrm{MN} / \mathrm{m}$ & $<0.1 \mathrm{MN} / \mathrm{m}$ & $<0.1 \%$ & $5 \mathrm{MPa}$ & $0.1 \%$ \\
Configuration 2 & $\boldsymbol{K}_{\mathbf{u}}$ & $\boldsymbol{K}_{\mathbf{d}}$ & $\boldsymbol{K}_{\mathbf{d}} / \boldsymbol{K}_{\mathbf{u}}$ & $\boldsymbol{E}_{\mathbf{m}}$ & $\boldsymbol{E}_{\mathbf{m}} / \boldsymbol{E}_{\mathbf{w}}$ \\
Specimen 10 & $5.5 \mathrm{MN} / \mathrm{m}$ & $0.1 \mathrm{MN} / \mathrm{m}$ & $1.2 \%$ & $182 \mathrm{MPa}$ & $1.2 \%$ \\
Specimen 14 & $3.8 \mathrm{MN} / \mathrm{m}$ & $<0.1 \mathrm{MN} / \mathrm{m}$ & $0.7 \%$ & $46 \mathrm{MPa}$ & $0.7 \%$ \\
Configuration 3 & $\boldsymbol{K}_{\mathbf{u}}$ & $\boldsymbol{K}_{\mathbf{d}}$ & $\boldsymbol{K}_{\mathbf{d}} / \boldsymbol{K}_{\mathbf{u}}$ & $\boldsymbol{E}_{\mathbf{m}}$ & $\boldsymbol{E}_{\mathbf{m}} / \boldsymbol{E}_{\mathbf{w}}$ \\
Specimen 10 & $5.5 \mathrm{MN} / \mathrm{m}$ & $0.4 \mathrm{MN} / \mathrm{m}$ & $7.2 \%$ & $710 \mathrm{MPa}$ & $7.2 \%$ \\
Specimen 14 & $3.8 \mathrm{MN} / \mathrm{m}$ & $0.3 \mathrm{MN} / \mathrm{m}$ & $6.6 \%$ & $440 \mathrm{MPa}$ & $6.6 \%$ \\
\hline \hline
\end{tabular}
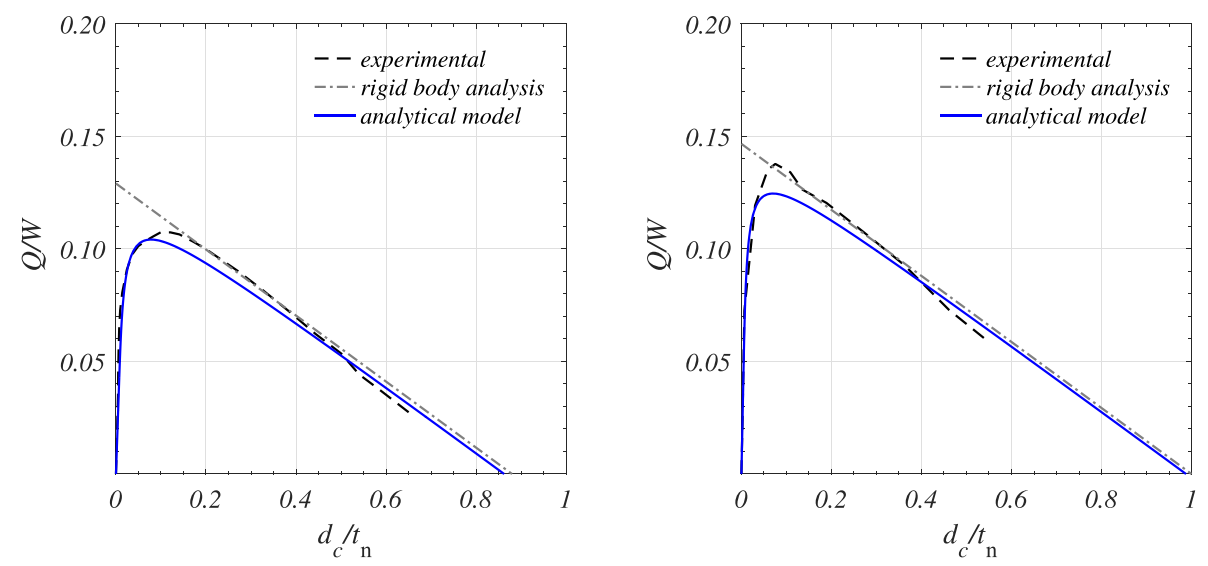

Specimen 11

Specimen 12

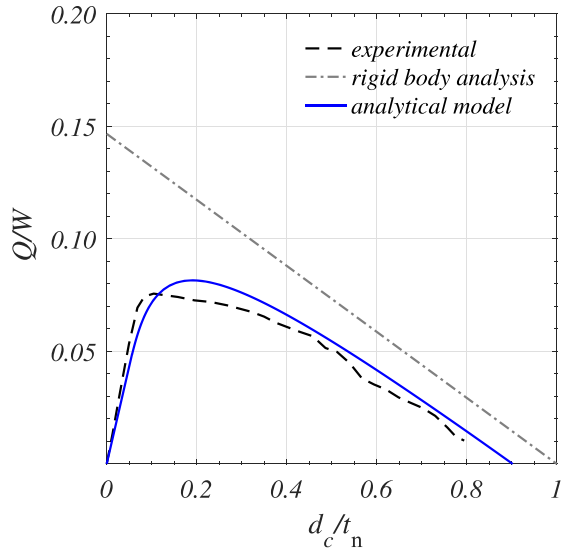

Specimen 13

FIGURE 7 Model validation based on the static pushover tests ${ }^{40}$ - Configuration 1 [Colour figure can be viewed at wileyonlinelibrary.com] 
the axial elongation was not restrained and the axial load was zero, the stiffness degradation was around $90 \%$ to $95 \% .{ }^{45}$ The increase in stiffness with increasing axial load ratio is in line with experimental findings on in-plane loaded walls. ${ }^{48-50}$

When validating the analytical model against the experimental results on the predamaged walls tested by Doherty et al., ${ }^{40,41}$ a value of $E_{\mathrm{m}}$ that is considerably lower than that obtained from classical compression tests needs therefore to be adopted. At the moment, there is no mechanical model for estimating the loss in stiffness of the mortar joints that could be used for predicting the ratio of the residual to the initial elastic modulus. For this reason, $E_{\mathrm{m}}$ was derived from the initial stiffness of the damaged walls. This latter was calculated as the secant stiffness $K_{\mathrm{d}}=192 E_{\mathrm{m}} I_{\mathrm{d}} / H^{3}$, measured at $1 / 5 Q^{\max }$ on the experimental curves, and computing the inertia $I_{\mathrm{d}}$ with the effective thickness of each specimen. $K_{\mathrm{d}}$ is the stiffness of a linear elastic clamped-clamped beam subjected to a concentrated load at midheight.

Table 2 gives the elastic moduli that are adopted in the analytical model when modelling the pushover tests performed by Doherty et al. ${ }^{40,41}$ The table also shows the reduction of stiffness measured between the response of the undamaged and the damaged walls. For this purpose, the initial stiffness of the damaged walls, $K_{\mathrm{d}}$, is compared to that of the undamaged walls $K_{\mathrm{u}}=192 E_{\mathrm{w}} I / H^{3}$, where for Specimen 11, the nominal thickness $t_{\mathrm{n}}$ is used instead of $t$. The so-obtained reductions of wall stiffness fall within the range of $0.1 \%-10 \%$ and $4 \%-30 \%$ observed by Derakhshan et al., ${ }^{12}$ respectively, for nonoverburdened and overburdened brick masonry walls. Notice that in Derakhshan et al., ${ }^{12}$ the undamaged stiffness was computed by taking into account a reduced thickness of the wall due to mortar pointing. This led to $K_{\mathrm{d}} / K_{\mathrm{u}}$ ratios that are, on average, slightly higher than those found herein. Moreover, in the case of walls with overburden (Configuration 3, Figure 9), the reduction of stiffness is smaller than for nonoverburdened walls, corroborating the dependence of the apparent elastic modulus on the overburden ratio, already observed by Derakhshan et al. ${ }^{12,45}$

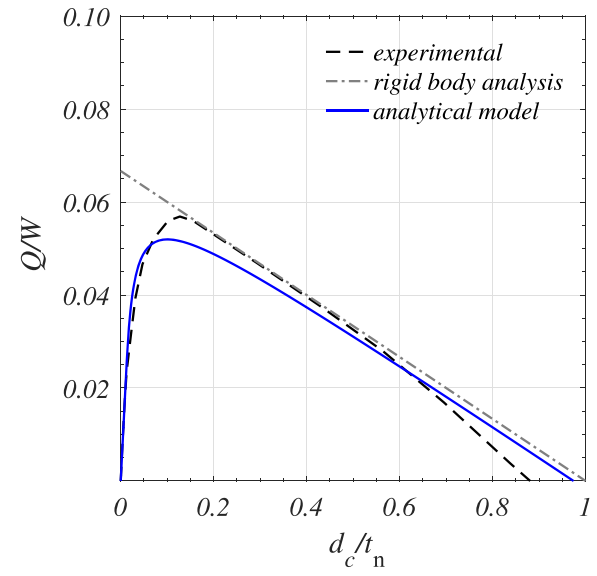

Specimen 10

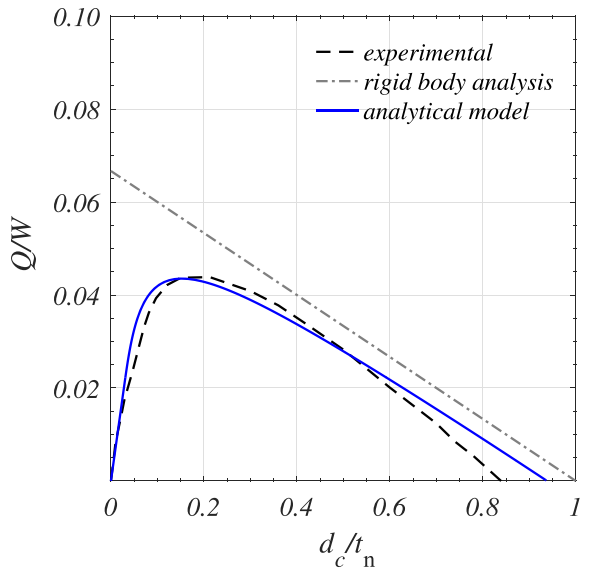

Specimen 14

FIGURE 8 Model validation based on the static pushover tests ${ }^{40}$ - Configuration 2 [Colour figure can be viewed at wileyonlinelibrary.com]

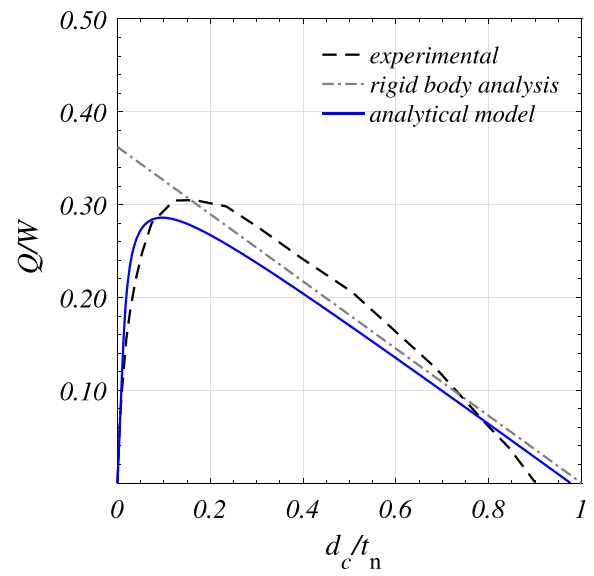

Specimen 10

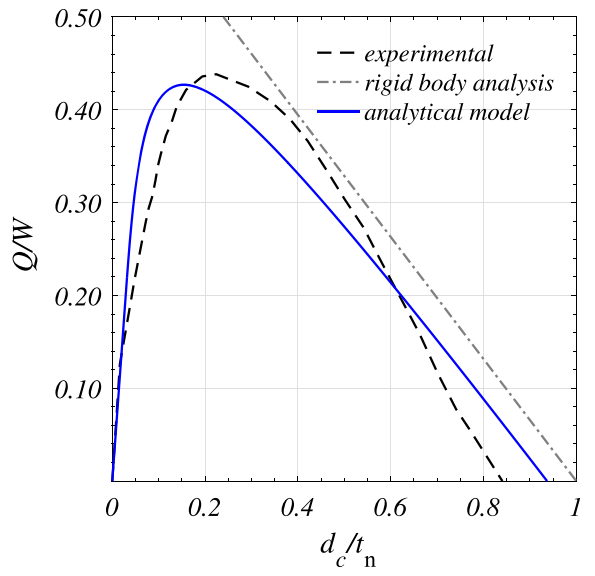

Specimen 14

FIGURE 9 Model validation based on the static pushover tests ${ }^{40}$ - Configuration 3 [Colour figure can be viewed at wileyonlinelibrary.com] 
TABLE 3 Prediction of the lateral strength (or peak force) of the walls tested at the University of Adelaide ${ }^{40}$ by means of the analytical model herein developed

\begin{tabular}{cccc} 
Configuration 1 & $Q_{\text {exp. }}^{\max }$ & $Q_{\text {anl. }}^{\max }$ & $Q_{\text {anl. }}^{\max } / Q_{\text {exp. }}^{\max }$ \\
\hline Specimen 11 & $297 \mathrm{~N}$ & $288 \mathrm{~N}$ & 0.97 \\
Specimen 12 & $381 \mathrm{~N}$ & $345 \mathrm{~N}$ & 0.91 \\
Specimen 13 & $209 \mathrm{~N}$ & $226 \mathrm{~N}$ & 1.08 \\
Configuration 2 & $Q_{\text {exp. }}^{\max }$ & $Q_{\text {anl. }}^{\max }$ & $Q_{\text {anl. }}^{\max } / Q_{\text {exp. }}^{\max }$ \\
Specimen 10 & $91 \mathrm{~N}$ & $84 \mathrm{~N}$ & 0.91 \\
Specimen 14 & $70 \mathrm{~N}$ & $70 \mathrm{~N}$ & 0.99 \\
Configuration 3 & $Q_{\text {exp. }}^{\max }$ & $Q_{\text {anl. }}^{\max }$ & $Q_{\text {anl. }}^{\max } / Q_{\text {exp. }}^{\max }$ \\
Specimen 10 & $490 \mathrm{~N}$ & $460 \mathrm{~N}$ & 0.94 \\
Specimen 14 & $705 \mathrm{~N}$ & $686 \mathrm{~N}$ & 0.97 \\
\hline
\end{tabular}

The comparison of the analytical pushover curves and the experimental pushover curves is shown in Figure 7 to Figure 9. The plots show that the analytical model is able to capture both the prepeak and the postpeak response of the walls. Furthermore, the analytical model allows to predict the peak force with an average error of less than $6 \%$ (Table 3 ).

\section{I EXPRESSION FOR THE LATERAL STRENGTH OF THE WALLS}

The lateral strength (or peak force) of the wall is a fundamental quantity of the out-of-plane response of unreinforced masonry walls. In this section, we derive formulas for the lateral strength of masonry walls subjected to concentrated lateral loads and extend these to walls subjected to uniformly distributed lateral loads.

\section{1 | Walls subjected to a lateral concentrated force}

Figure 10A shows the variation of the lateral load $Q^{e l}$ at the onset of cracking and of the peak force $Q^{\max }$ with the applied axial load $P$. Also shown in the figure is the maximum force $Q_{0}$, which is obtained from rigid body kinematic analysis of the collapse mechanism (Figure 4A). The force $Q^{e l}$ is obtained from Equation 7. The curve for $Q^{\max }$ is produced by computing the pushover curve for different values of axial load and collecting the maximum values of $Q$. By normalising the axial load $P$ by $P_{\mathrm{E}}$ and the lateral load $Q$ by $P t / H$, the curves for $Q^{m a x}, Q^{e l}$, and $Q_{0}$ depend only on $P / P_{\mathrm{E}}$ and the kinematic boundary conditions, but neither on the geometry $(H$ and $t)$ nor on the material property $\left(E_{\mathrm{m}}\right)$ of the wall. ${ }^{28,29,39}$

The curves in Figure 10A are plotted for concentric axial loads and for the 3 boundary conditions considered in this study. The variation of $Q^{\max }$ with $P$ was already plotted by Sahlin ${ }^{28}$ for pinned-pinned boundary conditions. For all 3 boundary conditions, the curves for $Q^{\max }, Q^{e l}$, and $Q_{0}$ show similar trends. For $P / P_{\mathrm{E}}=0$, the curve for $Q^{\max }$ tends towards that for $Q_{0}$. With increasing $P$, the curve for $Q^{\max }$ is monotonically decreasing and reaches zero for $P / P_{\mathrm{E}}=1$. The curve for the maximum force $Q_{0}$ predicted by rigid body analysis is, on the contrary, constant for all values of $P / P_{\mathrm{E}}$.

Figure 10B shows that the dependence of the ratios $Q^{\max } / Q^{e l}$ and $Q^{\max } / Q_{0}$ on $P / P_{\mathrm{E}}$ is, for all 3 boundary conditions, the same. In the 3 cases, the peak force is 1 to 3 times the force triggering cracking of the wall. Moreover, the ratio between $Q^{\max }$ and $Q_{0}$ always varies between 1 and 0 . As a result, the lateral strength (or peak force) of the wall can be expressed as follows:

$$
Q^{\max }=f\left(\frac{P}{P_{\mathrm{E}}}\right) Q_{0},
$$

where $P_{\mathrm{E}}$ is the Euler's critical axial load (Equation 13), $Q^{0}$ is given by the rigid body analysis of the wall for each of the boundary conditions herein considered (Figure 4$)$, and $f\left(P / P_{\mathrm{E}}\right)$ is a function of the form

$$
f\left(\frac{P}{P_{\mathrm{E}}}\right)=1-\sqrt{\frac{P}{P_{\mathrm{E}}}}
$$

fitting the $Q^{\max } / Q_{0}$ curves shown in Figure 10B, see Figure 11. 


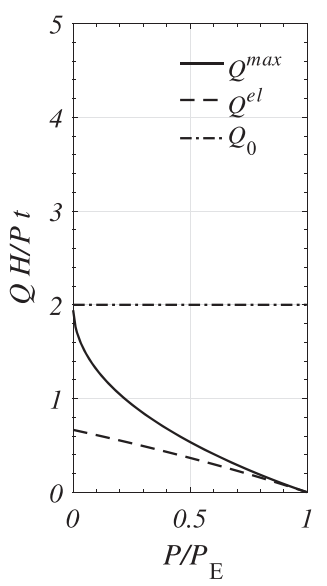

Pinned-pinned

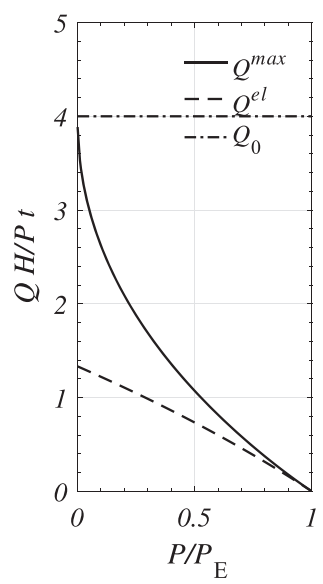

Clamped-clamped

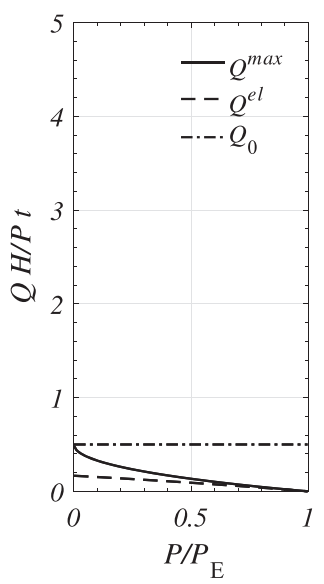

Cantilever

(A) Peak force $Q^{\max }$, force at the onset of cracking $Q^{e l}$ and force given by rigid body analysis $Q_{0}$

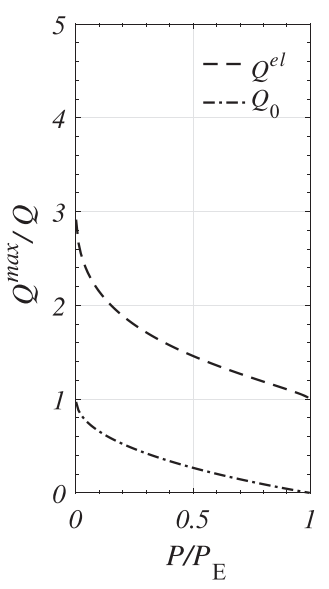

Pinned-pinned

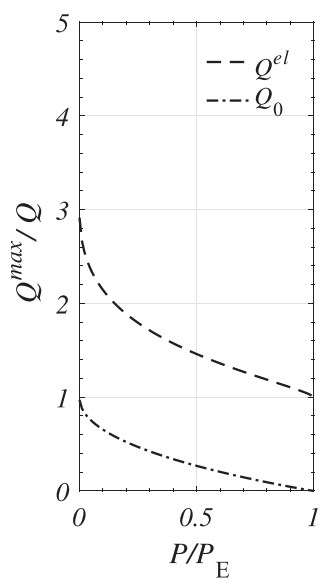

Clamped-clamped

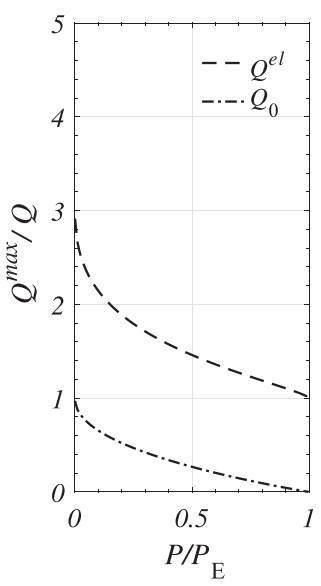

Cantilever

(B) Ratios $Q^{\max } / Q^{e l}$ and $Q^{\max } / Q_{0}$

FIGURE 10 Normalised lateral strength and force at the onset of cracking of vertically spanning masonry walls subjected to axial load $P$ and lateral concentrated force $Q$. A, Peak force $Q^{\max }$, force at the onset of cracking $Q^{e l}$, and force given by rigid body analysis $Q_{0}$; B, ratios $Q^{\max } / Q^{e l}$ and $Q^{\max } / Q_{0}$

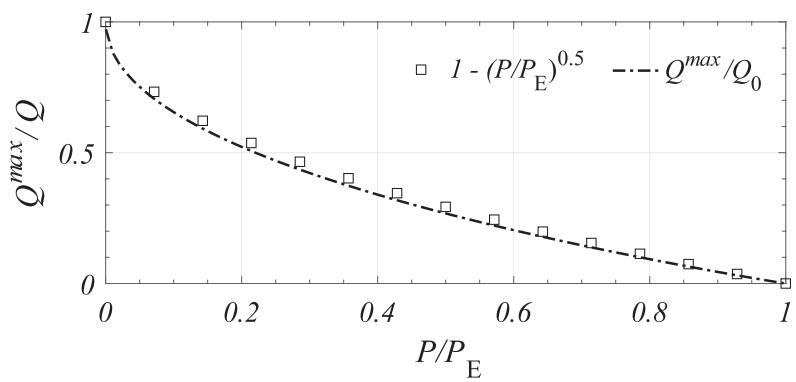

FIGURE 11 Equation 15

It is stressed that the behaviour of masonry in compression is assumed to be linear elastic. Equation 14 may therefore be applicable only within a certain range of axial loads $P$. Nonlinear constitutive laws used for compression show that material nonlinearities occur starting from approximately half the masonry compressive strength. ${ }^{18,20,32}$ During bending, masonry may therefore reach local compressive failure, which further diminishes the peak lateral force that the wall can sustain. ${ }^{26,30,31}$ To illustrate the range of applicability of Equation 14, the ratio $Q^{\max } / Q_{0}$ is plotted in Figure 12 versus the axial load ratio $P / P_{0}$. 


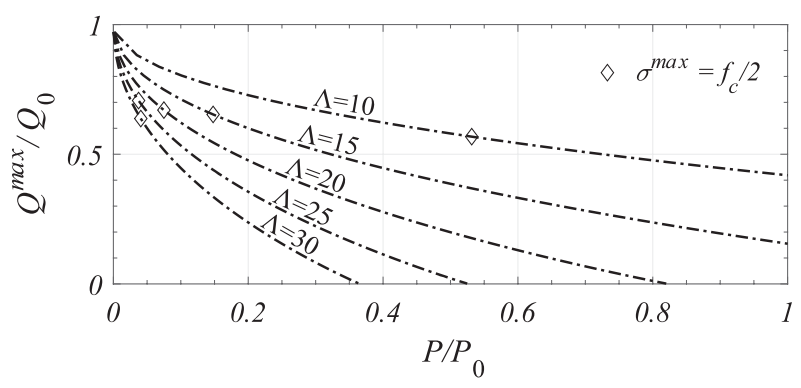

(A) Slenderness ratio $\Lambda\left(\Phi_{c}=400\right)$

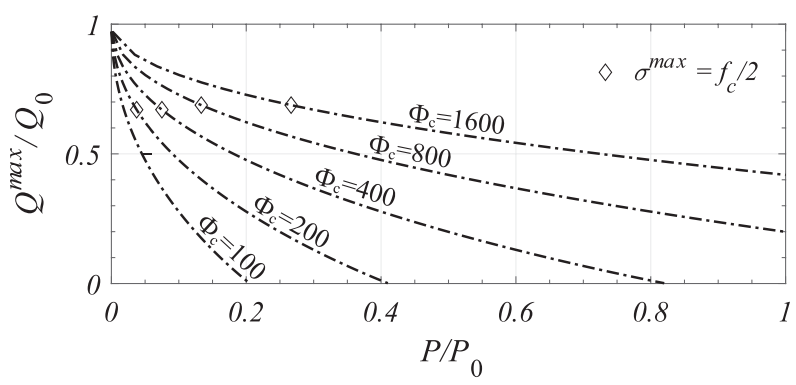

(B) Compressive strength ratio $\Phi_{c}(\Lambda=20)$

FIGURE 12 Variation of the $Q^{\max } / Q_{0}$ ratio versus the axial load ratio, for different values of wall slenderness and masonry compressive strength. Diamond-shaped markers refer to a wall subjected to lateral concentrated force, with $H=3 \mathrm{~m}$ and $f_{c}=10 \mathrm{MPa}$. A, Slenderness ratio $\Lambda\left(\Phi_{c}=400\right)$; B, compressive strength ratio $\Phi_{c}(\Lambda=20)$

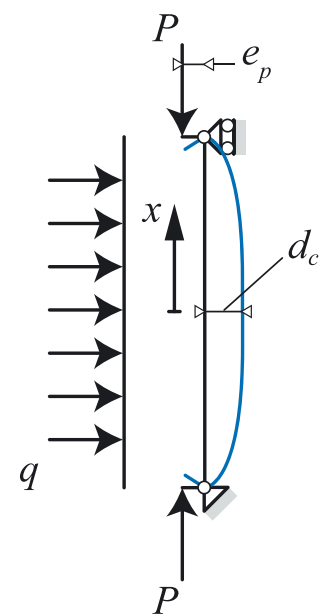

Pinned-pinned

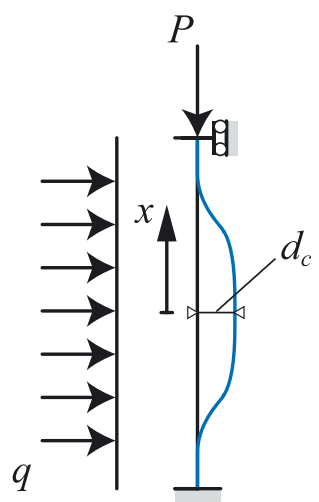

Clamped-clamped

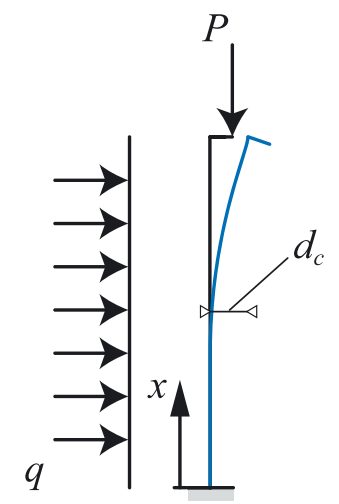

Cantilever

FIGURE 13 Vertically spanning masonry walls undergoing large out-of-plane deflections subjected to a lateral uniformly distributed load [Colour figure can be viewed at wileyonlinelibrary.com]

The axial load $P_{0}$ is the maximum compressive load that the wall can sustain. It is defined as $P_{0}=f_{c} L t$ and can be expressed in terms of the Euler's critical load as

$$
P_{0}=\frac{12}{\pi^{2}} \frac{\Lambda^{2}}{\Phi_{c}} P_{\mathrm{E}}
$$

with $\Lambda=H / t$ the slenderness ratio of the wall and $\Phi_{c}=E_{\mathrm{m}} / f_{c}$ the compressive strength ratio of the masonry. As expected, the ratio $Q^{\max } / Q_{0}$ decreases with increasing $\Lambda$ (Figure 12A) and increases with increasing $\Phi_{c}$ (Figure 12B). Diamond-shaped markers in Figure 12 correspond to points in which the maximum compressive stress at the outer fibre of the wall section (Equation 12) reaches $f_{c} / 2$ and the lateral strength of the wall can be compromised by local material nonlinearities. These points are geometry- and material-dependent and are computed here for a wall with $H=3 \mathrm{~m}$ and $f_{c}=10 \mathrm{MPa}$. 


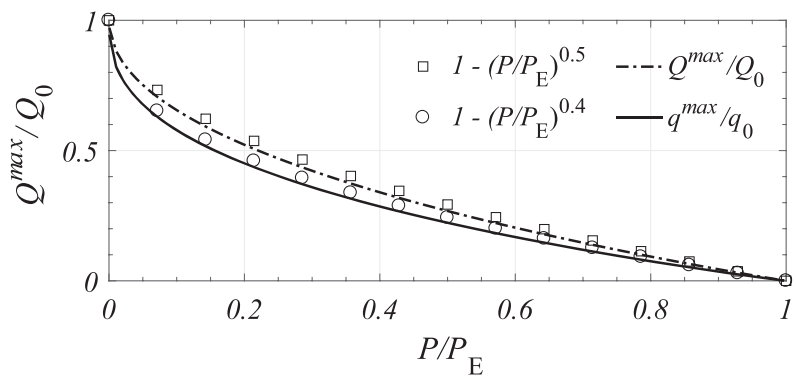

FIGURE 14 Comparison between the $q^{\max } / q_{0}$ ratio of masonry walls subjected to a distributed load with the $Q^{\max } / Q_{0}$ ratio of walls subjected to a concentrated load

\section{2 | Extension to walls subjected to lateral uniformly distributed load}

The analytical model is here applied to the second load case, which consists of a lateral uniformly distributed load $q$ and an axial load $P$. In this case, Heller's solution ${ }^{29}$ is used for the pinned-pinned wall and generalised to take into account two additional boundary conditions (Figure 13). For the sake of brevity, these solutions are given in Appendix B.

Figure 14 shows the comparison between the response obtained from masonry walls subjected to a concentrated load with those subjected to a distributed load. The comparison is shown for walls with pinned-pinned boundary conditions. As for concentrated loads, $q^{\max }$ corresponds to the maximum distributed load obtained with the here presented analytical model, and $q_{0}$ is the load derived from kinematic rigid body analysis. The difference between the normalised curves for the two load cases is relatively small. Based on these findings, Equations 14 and 15 can be also used for the load case of a distributed load. Figure 14 shows that a slightly enhanced estimation of the maximum load is obtained if Equation 14 is combined with Equation 17:

$$
f\left(\frac{P}{P_{\mathrm{E}}}\right)=1-\left(\frac{P}{P_{\mathrm{E}}}\right)^{0.4}
$$

\section{I CONCLUSIONS}

Displacement-based procedures for the assessment of out-of-plane loaded unreinforced masonry walls require the formulation of mechanical models that capture the complete force-displacement (or pushover) curve. This includes both the prepeak and the postpeak response of the walls.

In this paper, an analytical model describing the flexural response of slender vertically spanning unreinforced brick (or block) masonry walls was presented. The model was based on the second-order Euler-Bernoulli beam theory. Masonry was modelled as a material with zero tensile strength and linear elastic behaviour in compression. The resulting model equations were solved in an analytical way. For this purpose, solutions already presented in the literature for the stability (or buckling) analysis of masonry walls subjected to axial and lateral loads were here retrieved for two load cases and extended to cover a larger set of boundary conditions. The analytical expression of the force-displacement response of the walls was given in implicit form. These expressions can be straightforwardly implemented and used in displacement-based seismic assessment procedures.

The analytical model was validated against results from monotonic pushover tests on unreinforced vertically spanning brick masonry walls. The model provides a good level of accuracy in the simulation of the general shape of the curve and in particular of the peak strength of the wall, for which, so far, only an upper bound estimate by means of the rigid body kinematic analysis was available.

The peak strength might be of particular interest in design and assessment situations. Although an analytical solution was provided and nonlinear finite element simulations are therefore no longer necessary to estimate this peak strength, the solution of the analytical model presented here is considerably more complex than rigid body kinematic analysis. For this reason, the peak strength $Q^{\max }$ was expressed as a function of the force $Q_{0}$ obtained from rigid body kinematic analysis. It was shown that the following equation holds with good approximation for all boundary conditions:

$$
Q^{\max }=\left(1-\sqrt{\frac{P}{P_{\mathrm{E}}}}\right) Q_{0},
$$


where $P$ is the axial load applied to the top of the masonry wall and $P_{\mathrm{E}}$ the Euler's critical load of the wall. The lateral strength $Q^{\max }$ of the wall therefore depends not only on the wall geometry, boundary conditions, and material properties but also on the applied axial load. Unlike rigid body kinematic analysis would suggest, this dependency is not linear, which is reflected in the second term of Equation 18.

\section{ACKNOWLEDGEMENTS}

This work was prepared as part of the Basel-Project, which is supported by the Swiss Federal Office of the Environment and the Construction Department of the Canton Basel-Stadt. The authors would also like to thank Professor Michael Griffith, who furnished the dataset used for validation of the present research.

\section{REFERENCES}

1. Priestley MJN. Seismic behaviour of unreinforced masonry walls. Bull NZ Natl Soc Earthq Eng. 1985;18(2):191-205.

2. Makris N. The role of the rotational inertia on the seismic resistance of free-standing rocking columns and articulated frames. Bull Seismol Soc Am. 2014;104(5):2226-2239.

3. Lagomarsino S. Seismic assessment of rocking masonry structures. Bull Earthq Eng. 2015;13(1):97-128.

4. Doherty K, Griffith MC, Lam NTK, Wilson J. Displacement-based seismic analysis for out-of-plane bending of unreinforced masonry walls. Earthq Eng Struct Dyn. 2002;31:833-850.

5. NZSEE 2006. Assessment and improvement of the structural performance of buildings in earthquakes. Recommendations of a NZSEE Study Group on Earthquake Risk Buildings. New Zealand Society for Earthquake Engineering.

6. NTC 2008. Decreto Ministeriale 14/1/2008. Norme tecniche per le costruzioni. Ministry of Infrastructures and Transportations. G.U. S.O. n.30 on $4 / 2 / 2008 ; 2008$.

7. Sorrentino L, D'Ayala D, de Felice G, Griffith MC, Lagomarsino S, Magenes G. Review of out-of-plane seismic assessment techniques applied to existing masonry buildings. Int J Archit Herit. 2016;11(1):2-21.

8. Griffith MC, Magenes G, Melis G, Picchi L. Evaluation of out-of-plane stability of unreinforced masonry walls subjected to seismic excitation. J Earthq Eng. 2003;7(1):141-169.

9. D'Ayala D, Speranza E. Definition of collapse mechanisms and seismic vulnerability of historic masonry buildings. Earthq Spect. 2003;19(3):479-509.

10. Al Shawa OA, Felice G, Mauro A, Sorrentino L. Out-of-plane seismic behaviour of rocking masonry walls. Earthq Eng Struct Dyn. 2012;41(5):949-968.

11. Derakhshan H, Griffith MC, Ingham JM. Out-of-plane behavior of one-way spanning unreinforced masonry walls. J Eng Mech. 2013;139(4):409-417.

12. Derakhshan H, Griffith MC, Ingham JM. Airbag testing of multi-leaf unreinforced masonry walls subjected to one-way bending. Eng Struct. 2013;57:512-522.

13. Ferreira TM, Costa AA, Costa A. Analysis of the out-of-plane seismic behavior of unreinforced masonry: a literature review. Int J Archit Herit. 2014;9(8):949-972.

14. Royen N. Knickfestigkeit exzentrisch beanspruchter Saulen aus Baustoff der nur gegen Druck widerstandsfahig ist. Bauingenieur. 1937;18(444).

15. Angervo K. Uber die Knickung und Tragfahigkeit eines exzentrisch gedrucken Pfeilersohne Zugfestigkeit. In: Staatliche Technische Forschungsanstalt; 1954; Helsinki:Publication 26.

16. Chapman JC, Slatford J. The elastic buckling of brittle columns. Proc Insti Civil Eng. 1957;6(1):107-125.

17. Yokel FY, Methey RG, Dikkers RD. Strength of masonry walls under compressive and transverse loads. Technical Report 34, Washington D.C., National Bureau of Standards; 1971.

18. Romano F, Ganduscio S, Zingone G. Cracked nonlinear masonry stability under vertical and lateral loads. J Struct Eng. 1993;119(1):69-87.

19. Bean Popehn JR, Schultz AE, Lu M, Stolarski HK, Ojard NJ. Influence of transverse loading on the stability of slender unreinforced masonry walls. Eng Struct. 2008;30(10):2830-2839.

20. Cavaleri L, Fossetti M, Papia M. Modeling of out-of-plane behavior of masonry walls. J Struct Eng. 2009;135(12):1522-1532.

21. Frisch-Fay R. Stability of masonry piers. Int J Solids Struct. 1975;11(2):187-198.

22. Frisch-Fay R. Buckling of masonry pier under its own weight. Int J Solids Struct. 1980;16(5):445-450.

23. Frisch-Fay R. Stiffening effect of uncracked bricks in the stability of masonry piers. Int J Solids Struct. 1980;16(7):619-624.

24. La Mendola L, Papia M. Stability of masonry piers under their own weight and eccentric load. J Struct Eng. 1993;119(6):1678-1693.

25. La Mendola L, Papia M, Zingone G. Stability of masonry walls subjected to seismic transverse forces. J Struct Eng. 1995;121(November):1581-1587.

26. De Falco A, Lucchesi M. Stability of columns with no tension strength and bounded compressive strength and deformability. Part I: large eccentricity. Int J Solids Struct. 2002;39(25):6191-6210.

27. Fossetti M, Giacchino C, Minafò G. Stability analysis of clay brick masonry columns: numerical aspects and modelling strategies. Materials Struct. 2014;48(5):1615-1625. 
28. Sahlin S. Transversely loaded compression members made of materials having no tensile strength. In: IABSE, International Association for Bridge and Structural Engineering, Vol. 21; 1961; Zurich, Switzerland:243-253.

29. Hellers B. Eccentrically compressed columns without tensile strength subjected to uniformly distributed lateral loads. Technical Report 35 , Stockholm, National Swedish Institute for Building Reaserch; 1967.

30. Ganduscio S, Romano F. FEM and analytical solutions for buckling of nonlinear masonry members. J Struct Eng. 1997;123(1):104-111.

31. Schultz AE, Mueffelman JG. Elastic stability of URM walls under transverse loading. TMS J (The Masonry Society). 2003;21(1):31-40.

32. Lu M, Schultz AE, Stolarski HK. Application of the arc-length method for the stability analysis of solid unreinforced masonry walls under lateral loads. Eng Struct. 2005;27(6):909-919.

33. Gurel M. A, Pekgokgoz R. K, Cili F. Strength capacity of unreinforced masonry cylindrical columns under seismic transverse forces. Bull Earthq Eng. 2012;10:587-613.

34. Haller P. Load capacity of brick masonry. Designing, Engineering and Constructing with Masonry Products. Johnson FB. Gulf Publishing Company, Texas; 1969:129-149.

35. Makris N, Alexakis H. Limit equilibrium analysis of masonry buttresses and towers under lateral and gravity loads. Archi Appl Mech. 2015;85(12):1915-1940.

36. Benedetti A, Steli E. Analytical models for shear-displacement curves of unreinforced and FRP reinforced masonry panels. Constr Build Materials. 2008;22(3):175-185.

37. Petry S, Beyer K. Force-displacement response of in-plane-loaded URM walls with a dominating flexural mode. Earthq Eng Struc Dyn. 2015;44(14):2551-2573.

38. Wilding BV, Beyer K. Force-displacement response of in-plane loaded unreinforced brick masonry walls: the Critical Diagonal Crack model. Bull Earthq Eng. 2016;15(5):1-44.

39. Sahlin S. Structural Masonry. Englewoods. New Jersey: Prentice Hall; 1971.

40. Doherty K. An investigation of the weak links in the seismic load path of unreinforced masonry building. Ph.D. Thesis: University of Adelaide; 2000.

41. Griffith MC, Lam NTK, Wilson JL, Doherty K. Experimental investigation of unreinforced brick masonry walls in flexure. J Struct Eng. 2004;130(3):423-432

42. Graziotti F, Tomassetti U, Penna A, Magenes G. Out-of-plane shaking table tests on URM cavity walls. Eng Struct. 2016;125:1939-1947.

43. Dazio A. The effect of the boundary conditions on the out-of-plane behaviour of unreinforced masonry walls. In: Proceedings of the 14th World Conference on Earthquake Engineering, Beijing; 2009.

44. Tondelli M, Beyer K, DeJong MJ. Influence of boundary conditions on the out-of-plane response of brick masonry walls in buildings with RC slabs. Earthq Eng Struct Dyn. 2016;41(11):1-12.

45. Derakhshan H, Dizhur D, Griffith M, Ingham J. In situ out-of-plane testing of as-built and retrofitted unreinforced masonry walls. J Struct Eng. 2014;140(6):4014022.

46. Candela M, Cattari S, Lagomarsino S, Fonti R. In-situ tests on the in-plane and out-of-plane behavior of irregular stone masonry. In: Proceedings of XV national conference ANIDIS Seismic Engineering in Italy; 2013; Padova; 1-37.

47. de Felice G. Out-of-plane seismic capacity of masonry depending on wall section morphology. Int J Archit Herit. 2011;5(4-5):466-482.

48. Vanin F, Zaganelli D, Penna A, Beyer K. Estimates for the stiffness, strength and drift capacity of stone masonry walls based on 123 quasi-static cyclic tests reported in the literature. Submitted. 2017.

49. Bosiljkov V, Totoev Y, Nichols J. Shear modulus and stiffness of brickwork masonry: an experimental perspective. Struct Eng Mech. 2005;20:21-43.

50. Vasconcelos G. Experimental investigations on the mechanics of stone masonry: characterization of granites and behavior of ancient masonry shear walls. Ph.D. Thesis: University of Minho, Portugal; 2005.

How to cite this article: Godio M, Beyer K. Analytical model for the out-of-plane response of vertically-spanning unreinforced masonry walls. Earthquake Engng Struct Dyn. 2017;1-20. https://doi.org/10.1002/eqe.2929

\section{APPENDIX A: CONTRIBUTION OF THE SELF-WEIGHT ON THE WALL RESPONSE}

The wall self-weight is not included in the analytical model as distributed gravity load over the wall height. To take into account its effect on the wall response, the axial load $P$ at the top of the wall can be set to

$$
P=O+\beta W,
$$

where $O$ is the axial overburden, $W$ is the total wall self-weight, and $\beta$ is a parameter taking into account various boundary conditions of the wall (Section 3.1). For the cantilever wall, one has also to replace the factor $\beta / \alpha$ with the factor $\omega=(O+W) /(O+W / 2)$ in Equations 6, 8, and 10. This approach allows to obtain force-displacement curves that are consis- 


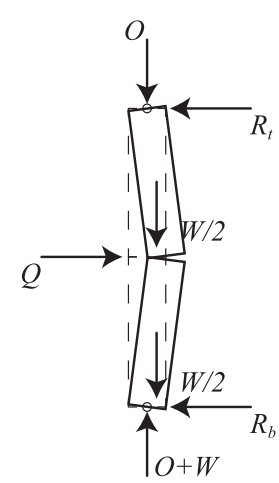

Pinned-pinned

$$
Q_{0}=\frac{4}{H}\left[\frac{t}{2}\left(O+\frac{W}{2}\right)\right]
$$$$
\Delta_{0} / t=1 / 2
$$

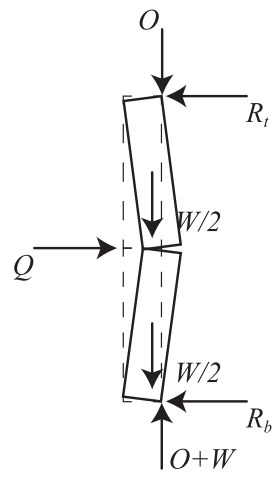

Clamped-clamped

$Q_{0}=\frac{4}{H}\left[t\left(O+\frac{W}{2}\right)\right]$

$\Delta_{0} / t=1$

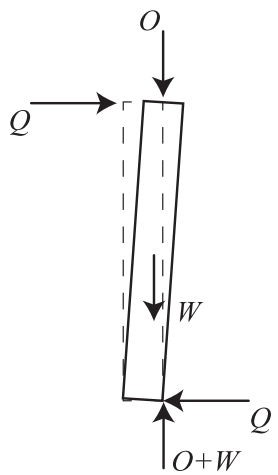

Cantilever

$$
\begin{gathered}
Q_{0}=\frac{1}{H}\left[\frac{t}{2}(O+W)\right] \\
\Delta_{0} / t=(1 / 2) \omega
\end{gathered}
$$

FIGURE A1 Rigid body analysis of vertically spanning walls with self-weight applied. $Q_{0}$ and $\Delta_{0}$ are the maximum lateral force and the maximum displacement at the control node, respectively

tent with those given by rigid body analysis of the walls when the self-weight is applied at the centre of mass of each block and the third hinge develops at wall midheight (Figure A1). For the influence of the self-weight on the position of the third hinge, see Derakhshan. ${ }^{11}$

\section{APPENDIX B: ANALYTICAL SOLUTIONFOR WALLS SUBJECTED TO LATERAL DISTRIBUTED LOAD}

\section{B.1 Response of the uncracked wall}

The response of the wall prior to cracking is given by the following expressions (Equation 1):

$$
\begin{aligned}
& \delta_{c}=-\frac{1}{t}\left(\sec \left(\frac{\mu H}{2}\right)-1\right) e_{p}-\frac{1}{\mu^{4} t E_{\mathrm{m}} I}\left(1+\frac{\mu^{2} H^{2}}{8}-\sec \left(\frac{\mu H}{2}\right)\right) q \\
& \delta_{c}=\frac{1}{t}\left(\sec \left(\frac{\mu H}{2}\right)-1\right) e_{p}+\frac{1}{\mu^{4} t E_{\mathrm{m}} I}\left(1+\frac{\mu^{2} H^{2}}{24}+\left(\frac{\mu^{2} H^{2}}{12}-1\right) \sec \left(\frac{\mu H}{2}\right)\right) q \\
& \delta_{c}=\frac{1}{t}(\sec (\mu H)-1) e_{p}+\frac{1}{\mu^{4} t E_{\mathrm{m}} I}\left(1-\frac{\mu^{2} H^{2}}{2}+\mu H \tan (\mu H)-\sec (\mu H)\right) q .
\end{aligned}
$$

The above expressions apply respectively for the pinned-pinned, clamped-clamped, and cantilever wall (Figure 13).

\section{B.2 Onset of cracking}

Cracking is triggered in the masonry walls when the distributed load equals the elastic limit $q^{e l}$. For the pinned-pinned and cantilever wall, this limit reads (Equation 1 and 3)

$$
\begin{aligned}
q^{e l} & =-\frac{1}{2} \mu^{4} E_{\mathrm{m}} I \csc ^{2}\left(\frac{\mu H}{4}\right) e_{p}+\frac{\mu^{2}}{\sec \left(\frac{\mu H}{2}\right)-1} \frac{t}{6} P \\
q^{e l} & =-\frac{\mu^{4} E_{\mathrm{m}} I \sec (\mu H)}{\mu H \tan (\mu H)-\sec (\mu H)+1} e_{p}+\frac{\mu^{2}}{\mu H \tan (\mu H)-\sec (\mu H)+1} \frac{t}{6} P,
\end{aligned}
$$

and it corresponds to the normalised deflections (Equation 8):

$$
\begin{aligned}
& \delta_{c}^{e l}=\frac{1}{t}\left(\frac{t}{6}-e_{p}-\frac{q^{e l}}{2 P} \frac{L^{2}}{4}\right) \\
& \delta_{c}^{e l}=\frac{1}{t}\left(\frac{t}{6}-e_{p}-\frac{q^{e l}}{2 P} L^{2}\right) .
\end{aligned}
$$


For the clamped-clamped wall, cracking occurs for the first time at the ends of the wall, when the distributed load and the deflection reach the following values:

$$
\begin{aligned}
& q^{e l}=-\frac{2 \mu^{2} t}{\left(\mu^{2} H^{2}-12\right) \sec \left(\frac{\mu H}{2}\right)+12} P-\frac{12 \mu^{4} E_{\mathrm{m}} I}{\mu^{2} H^{2}+12 \cos \left(\frac{\mu H}{2}\right)-12} e_{p} \\
& \delta_{c}^{e l}=\frac{1}{t}-\frac{t\left(2 \mu^{2} H^{2}+\left(\mu^{2} H^{2}+24\right) \cos \left(\frac{\mu H}{2}\right)-24\right)}{12 \mu^{2} E_{\mathrm{m}} I\left(\mu^{2} H^{2}+12 \cos \left(\frac{\mu H}{2}\right)-12\right)} P-\frac{3\left(\mu^{2} H^{2}+8 \cos \left(\frac{\mu H}{2}\right)-8\right)}{2 \mu^{2} H^{2}+24 \cos \left(\frac{\mu H}{2}\right)-24} e_{p} .
\end{aligned}
$$

\section{B.3 Response of the partially cracked wall}

Hellers ${ }^{29}$ showed that the solution for a partially cracked masonry wall that is pinned at both ends and loaded laterally by a uniformly distributed load is given in implicit form. This form is here generalised to cover 2 additional cases that are of practical interest that is the clamped-clamped and the cantilever wall. The general solution writes

$$
\begin{aligned}
\mu \alpha H & -\frac{2 k}{1-k^{2}}(1-p)^{3 / 2}\left(\Psi(k, \phi)-\mathcal{E}(k, \phi)+\left(1-k^{2}\right) \mathcal{F}(k, \phi)\right)+ \\
& -\arcsin \left(\frac{1+2 R}{\sqrt{4 R(2 p+R+1)+\frac{3 p+1}{1-p}}}\right)+\arcsin \left(\frac{m+2 R}{\sqrt{4 R(2 p+R+1)+\frac{3 p+1}{1-p}}}\right)=0,
\end{aligned}
$$

where the functions $\Psi(k, \phi), \mathcal{E}(k, \phi), \mathcal{F}(k, \phi)$ used in the expression are defined as

$$
\begin{aligned}
& \Psi(k, \phi)=\tan (\phi) \sqrt{1-k^{2} \sin ^{2}(\phi)} \\
& \mathcal{E}(k, \phi)=\int_{0}^{\phi} \sqrt{1-k^{2} \sin ^{2}(\phi)} \mathrm{d} \phi \\
& \mathcal{F}(k, \phi)=\int_{0}^{\phi} \frac{1}{\sqrt{1-k^{2} \sin ^{2}(\phi)}} \mathrm{d} \phi,
\end{aligned}
$$

with the following notation

$$
\begin{aligned}
p & =\frac{3}{t}\left(u_{c}-\frac{t}{6}\right) \\
m & =\frac{6}{t} e_{p} \\
\phi & =\arcsin (\sqrt{p}) \\
R & =\frac{1}{4} \frac{\beta}{\alpha} E_{\mathrm{m}} \frac{q}{L}\left(\frac{t L}{P}\right)^{2} \\
k & =\frac{1}{\sqrt{2(1-p)^{2} R+1}} .
\end{aligned}
$$

In the above expressions, $u_{c}$ has the same expression than Equation 10. Therefore, it can be linked to the normalised displacement $\delta_{c} . M_{c}$ is a function of the distributed load $q$, which is herein expressed in N/m (cf Hellers $\left.{ }^{29}\right): M_{c}=\beta(\alpha H)^{2} q /(2 \alpha)$. 